\title{
Los acuerdos entre los Estados Unidos y la Unión de las Repúblicas Socialistas Soviéticas
}

\author{
INTRODUCCIÓN
}

\section{Las 12 hipótesis principales}

1) Nueva Era: Ios Acuerdos firmados por las dos superpotencias en Moscú y en Washington, en 1972 y 1973, significan el comienzo oficial, formal, de una nueva era en el campo de las relaciones internacionales y de la política mundial.

2) Fin de Guerra Fría: la nueva era de las relaciones internacionales y de política mundial implica la terminación -oficial y formal de la guerra fría- en sus esquemas mentales y estratégicos y el comienzo de una etapa de distensión y de reestructuración de las relaciones entre las dos superpotencias.

3) Cambio Político Mundial: el establecimiento de profundas relaciones de colaboración entre las dos superpotencias impone, necesariamente, -por el contenido, por la magnitud y por su significado con relación a las superpotencias y a los terceros países- un cambio en la política mundial.

4) Las Magnitudes de las Superpotencias: la interpretación y la evaluación de los Acuerdos de Moscú y de Washington deben realizarse en función de las magnitudes del poder de las superpotencias; en función del contenido de los Acuerdos; y en función de su contexto histórico.

5) Contexto Histórico: Ios efectos de los Acuerdos de Moscú y de Washington podrán valorarse en sus últimas consecuencias si se tiene en cuenta que el contexto histórico de la era científico-tecnológica ha alterado radicalmente el significado del espacio (distancia) y del "tempo" o "timing".

6) Contenido de los Acuerdos: Ios Acuerdos de Moscú y de Washington, regulan sectores claves de las relaciones entre las dos superpo- 
tencias y por su contenido trascienden a los intereses de las partes contratantes:

a) Principios Básicos de las relaciones entre los Estados Unidos y la Unión de Repúblicas Socialistas Soviéticas: contactos, intercambios, cooperación.

b) Limitación de armamentos estratégicos y prevención de la guerra nuclear e incidentes marítimos.

c) Cooperación en ciencia y técnica, salud, medio ambiente, agricultura, transporte, impuestos.

7) Medidas del Superpoder: los Estados Unidos y la Unión de Repúblicas Socialistas Soviéticas -en conjunto- representan el 45 por ciento del producto interno bruto mundial, y más del 95 por ciento del poder nuclear y prácticamente el 100 por ciento del poder espacial.

8) Efectos de la Distensión: la distensión de las relaciones internacionales y la reestructuración profunda de las relaciones entre los Estados Unidos y la Unión de Repúblicas Socialistas Soviéticas liberan la supercapacidad -financiera, científico-tecnológica y de organización y dirección- de las superpotencias y plantean dramáticamente la urgencia de reorientar y canalizar esa supercapacidad hacia fines pacíficos del desarrollo mundial.

9) Seguridad Internacional: la seguridad internacional no se limita solamente a la ausencia de conflictos entre las superpotencias y debe extenderse geográficamente hacia todos los países del mundo. Y paz no es sinónimo de no-guerra, sino que comprende aspectos sociales, culturales, económicos, políticos y ecológicos. En este sentido los Acuerdos de Moscú y de Washington son condición necesaria, pero de ningún modo condición suficiente para la seguridad y la paz mundial.

10) Guerra Nuclear y Paz Nuclear: la era científico-tecnológica se caracteriza principalmente por el uso de la energía nuclear $y$, en consecuencia, enfrenta a la humanidad con el peligro de una guerra nuclear. Todos apreciamos el riesgo generacional que representa la guerra nuclear. Pero resulta evidente que en la era nuclear tendremos también una paz nuclear. Y si es urgente controlar en forma segura y terminante a los conflictos nucleares, también lo es el construir las bases duraderas de la paz nuclear.

11) Los Desafios a los Acuerdos: los Acuerdos de Moscú y de Washington enfrentan -en este momento histórico- dos pruebas de fondo: una de carácter internacional: el conflicto del Medio Oriente; 
Horacio H. Godoy / Los acuerdos entre los E.E. U.U. y la U.R.S.S.

otra de carácter interno que afecta a las partes: la enmienda del senador Henry Jackson al Tratado de Comercio Soviético-Norteamericano, con el fin de evitar que se reconozca la condición de NMF a la Unión Soviética, mientras perdure el régimen de discriminación con respecto a la emigración de la Unión de Repúblicas Socialistas Soviéticas de los ciudadanos de origen judío que deseen salir.

12) Extensión Universal de los Principios: para asegurar la validez universal de los Acuerdos de Moscú y de Washington, deberían extenderse sus principios y sus aspiraciones a un entendimiento profundo, a todos los países de la tierra. Esta universalización de las condiciones de la paz exige sistemas y mecanismos nuevos en escala mundial que estimulen, fortalezcan y canalicen la participación de todos los países en la toma de decisiones de trascendencia mundial. Nunca como ahora, la Organización de las Naciones Unidas ha sido considerada por la mayoría de los países de la tierra como el organismo histórico encargado de universalizar la paz en los hechos. Pero ello tendrá necesariamente que -con el apoyo de todos los pueblos que reclaman y esperan su acción mundial efectiva - constituir los mecanismos necesarios y disponer de los recursos financieros y técnicos para cumplir su histórica misión.

EL MARCO HISTÓRICO DE LOS ACUERDOS

\section{La aceleración de la historia y las relaciones internacionales}

La aceleración de la historia, en nuestra era espacial, es un hecho que se reconoce sin mayor dificultad, pero que, generalmente, no alcanza a valorarse suficientemente. Es tal la rapidez con que suceden los acontecimientos más importantes y variados en el campo científico-tecnológico, en las actividades políticas y en el ámbito internacional que resulta difícil -si no imposible- al hombre de nuestro tiempo mantenerse siquiera superficialmente informado acerca de los grandes hechos contemporáneos. Una verdadera "explosión de información" transmitida cada vez con más rapidez y aumentando en forma rápida su contenido, sobrepasa las limitadas capacidades de la inteligencia humana para absorber, analizar, comprender y evaluar su significado. ${ }^{1}$

${ }^{1}$ Alvin Toffler: The Future Shock, Random House, New York, 1970, pp. 311/316. Marshall McLuhan and Quentin Fiore: The Medium is the MassageAn Inventory of Effects, Penguin Books, 1967. Gaudium et Spes, Constitución Conciliar: La Iglesia en el Mundo de Hoy, Ediciones Paulinas, Santiago, 1966. 
El campo de la política internacional es uno de los que presentan más acontecimientos de extraordinaria importancia que suceden en forma vertiginosa, y que han cambiado la faz del mundo, especialmente sus proyecciones hacia el futuro en estos próximos 30 años. El período de 1971-1973, ha sido testigo de una serie de hechos cuyos efectos en la orientación general de la política internacional parecen estar fuera de discusión. Mencionaré cronológicamente, los siguientes acontecimientos:

1) El 25 de octubre de 1971, la Asamblea General de las Naciones Unidas reconoció como único representante de la China al gobierno de la República Popular China y los colaboradores de Mao Tse Tung ingresaron al Consejo de Seguridad y ocuparon posiciones en los diversos organismos de la Sede Central y de las demás organizaciones de las Naciones Unidas;

2) El 22 de enero de 1972, Gran Bretaña se incorporó a la Comunidad Económica Europea, iniciando de esta manera lo que se llamó "la segunda generación" de la Comunidad;

3) En el mes de febrero de 1972, el presidente Richard Nixon realizó su histórica visita a China, estrechando la mano de Mao Tse Tung e iniciando así, oficialmente, una política de acercamiento progresivo entre los Estados Unidos de América y la República Popular China;

4) Entre el 22 y el 30 de mayo de 1972 , se produce la primera visita oficial de un presidente de los Estados Unidos a la Unión Soviética ${ }^{2}$, y se firman los acuerdos bilaterales a los que nos referiremos más adelante;

5) En octubre de 1972, las negociaciones de paz en Vietnam toman una definitiva orientación hacia su solución final y se concretan hacia fines del año y comienzos de 1973;

6) Entre los días 18 y 25 de junio de 1973 , el secretario general del Partido Comunista Soviético, Leonidas I. Brézhnev, realiza su visita a los Estados Unidos y firma con el presidente Nixon una serie de acuerdos bilaterales que complementan y amplían los acuerdos de Moscú del año anterior y, finalmente,

2Desde el año 1959, fecha en que Nikita Kruschev visitó al Presidente Eisenhower, las máximas autoridades de las superpotencias han celebrado las siguientes reuniones: John F. Kennedy y Nikita Kruschev en Viena, 1961; Lyndon B. Johnson y Alexei Kosygin en Glassboro, Estados Unidos, con ocasión de la asistencia del premier soviético a la Asamblea General de las Naciones Unidas; $y$, finalmente, las dos entrevistas mencionadas del Presidente Richard Nixon con el Secretario General del Comité Central del Partido Comunista de la Unión Soviética, Leonidas I. Brézhnev, en mayo de 1972 y en junio de 1973. 
IIoracio H. Godoy / Los acuerdos entre los E.E. U.U. $y$ la U.R.S.S.

7) El 18 de setiembre de 1973, la Asamblea General de las Naciones Unidas en su vigésimo octavo período de sesiones, admitió por aclamación el ingreso a las Naciones Unidas de la República Federal Alemana y de la República Democrática Alemana.

Los antecedentes señalados, más los acuerdos tan importantes como tan poco difundidos, firmados entre los Estados Unidos de América y la Unión Soviética sobre Intercambio y Cooperación en los campos Científico, Técnico, Educativo, Cultural y otros campos, y los acuerdos sobre Cooperación Espacial (explotación y utilización del espacio exterior; el rescate de astronautas; el regreso de astronautas y el regreso de los objetos lanzados al exterior; y el desarrollo de los sistemas compatibles para la cita y el acoplamiento de naves tripulantes y estaciones espaciales de los Estados Unidos y de la Unión Soviética), del mes de abril de 1972, son los signos visibles de la profunda transformación que está viviendo la política mundial en el último cuarto del siglo xx. Además, la famosa ostpolitik del canciller Willy Brandt constituye otra de las manifestaciones señaladas que afirman esta tendencia profunda de cambio sustantivo en las relaciones internacionales. Los tratados de la República Federal Alemana con la Unión Soviética (12 de agosto de 1970) y con la República Popular de Polonia (7 de diciembre de 1970) son dos expresiones concretas del cambio. Con razón pudo decir el canciller alemán, Willy Brandt, al firmar el tratado con la Unión Soviética, que "nosotros tenemos el valor de pasar a una nueva página en la historia"."

Estos acontecimientos son, a la vez, testimonio de lo que Alvin Toffler ha llamado "el shock del futuro", porque son hechos históricos que han llegado a nosotros, antes de lo que esperábamos. ${ }^{4}$

\section{La disminución del tamaño relativo del mundo}

Pero hay otra dimensión en nuestro análisis de las relaciones internacionales y que, junto a la aceleración de la historia, constituye un

3Willy Brandt: Paz: Discursos y Escritos del Titular del Prebio Nóbel de la Paz, 1971. Verlag Neue Geselschaft, GmbH, Alemania, 1971, p. 117. Para la política exterior de Alemania Federal, ver Karl Kaiser: German Foreign Policy in Transition, Oxford University Press, London, Oxford, New York, 1968. Para los Acuerdos firmados entre la RFD y la Unión Soviética y la RFD' y la República Popular de Polonia, ver: The Treaty of August 12, 1970 Between the Federal Republic of Germany and the Union of Soviet Socialist Republics, Press and Information Office of the Government, Printed in Germany, 1970; y Tratado entre la República Federal Alemana y la República Popular de Polonia, Departamento de Prensa e Información del Gobierno Federal.

${ }_{4}^{4}$ Alvin Toffler, op. cit. 
factor estructural determinante de la situación contemporánea. Me refiero a lo que se ha denominado la disminución del tamaño relativo del mundo, en función de la velocidad y el alcance de los nuevos medios de comunicación y de transporte. En base a estos modernos instrumentos, puede decirse que "el tamaño relativo del mundo es inversamente proporcional a la velocidad con que el hombre recorre las distancias". ${ }^{5}$

En los últimos cien años, las velocidades regulares han pasado de 100 kilómetros por hora a más de 1.000 kilómetros por hora, y el salto a las velocidades de lanzamiento de cohetes cargados con ojivas nucleares, y a la velocidad de los satélites artificiales, pasa a los 10.000 y 35.000 kilómetros, respectivamente. Este salto cualitativo transforma el sentido de las distancias, reduciendo el tamaño relativo del mundo en proporción a las nuevas velocidades alcanzadas. En el campo del transporte de personas, de bienes, de servicios y de bombas nucleares, las distancias han desaparecido tanto para las superpotencias que disponen de esos medios nuevos de comunicación y de transporte, cuanto para los países que no disponen de tales instrumentos modernos, porque al desaparecer las distancias, la lejanía de los centros de poder mundial ya no tiene mayor significado para la mejor defensa de los países débiles.

La combinación de la reducción del tamaño relativo del mundo y la aceleración de la historia contemporánea, produce entre otros, los siguientes efectos en el campo específico de las relaciones internacionales:

Primero: la acentuación del proceso de globalización en escala mundial, fortaleciendo las relaciones de interacción recíproca entre todos los estados del mundo ("global village"). ${ }^{6}$

Segundo: la acentuación del proceso de globalización en escala mundial, va acompañado por subprocesos en la estructuración del poder mundial que se caracterizan por un doble movimiento: por una parte, una fuerte tendencia hacia la concentración del poder

\footnotetext{
5Horacio H. Godoy: The Matrix for Contextual-Systemic-Operational Analysis: contribution to the elaboration of preferred World Order Models, Third Conference of Research Directors, Kampala, Uganda, 1969, y Aspectos Políticos de la Revolución Científico-Tecnológica de Nuestro Tiempo, en: "Inversiones Extranjeras y Transferencia de Tecnología en América Latina", K. H. Stanzick y Horacio H. Godoy, Editores, Santiago, Chile, 1972, pp. 37/48. Ver además, Stanford Research Institute: Non Military Scientific Development and their Potential Impact on Foreign Policy, Committee of Foreign Relations, USA Senate, Government Printing Office, Washington, D.C., 1960, pp. 97/198. World Facts and Trends. Center for Integrative Studies, School of Advanced Technology, State University of New York, Binghamton, New York, 1970, p. 30.

6Marshal McLuhan, Quentin Fiore y Jerome Agel: Guerra y Paz en la Aldea Global, Ediciones Martínez Roca, S.A., Barcelona, 1970, p. 19.
} 
mundial en dos superpotencias, cuyas dimensiones de poder exceden la capacidad de imaginación convencional y en no más de tres grandes potencias (China, Japón y la Comunidad Económica Europea) y, como un hecho propio de nuestra era, la aparición de las grandes empresas transnacionales ${ }^{7}$ que por sí mismas, constituyen una de las columnas vertebrales de la nueva estructuración del poder mundial. Pero el proceso del poder mundial presenta otra tendencia que es hacia la dispersión del poder y se manifiesta en la proliferación de naciones-estados jurídicamente independientes, muchas de las cuales merecen la calificación de "mini-estados".

Esta "explosión de países" que incorpora a la vida jurídica independiente a estados como las Islas Maldivas, Trinidad-Tobago, las Bahamas, las Islas Fiji, etc., es la que ha producido el crecimiento masivo de los países miembros de la Organización de las Naciones Unidas que, en 1945, eran sólo 51 y ahora llegan a 135 con la reciente incorporación de las dos Alemanias. Los países que no están formalmente alineados con las superpotencias, tratan en las más diversas formas de reunir su poder disperso desde las negociaciones en el campo del comercio y del desarrollo dentro de la UNCTAD, hasta las conferencias de los países no alineados. ${ }^{9}$

Finalmente, cabe señalar que la aceleración de la historia y esta reducción del tamaño relativo del mundo en función de la velocidad y el alcance de los medios modernos de comunicación y de transporte, por una parte, y el proceso de estructuración del poder mundial contemporáneo, con el doble movimiento de concentracióndispersión -nuevas formas de concentración-, por la otra, van acompañados por otros problemas de vital importancia para el género

7Horacio H. Godoy: La Administración Pública, las Empresas Transnacionales y el Grupo Andino, Escuela Superior de Administración Pública, Bogotá, 1973, pp. 19/46. United Nations: Multinational Corporations and World Development, New York, 1973. César Sepúlveda: Las llamadas Empresas Multinacionales, México, D.F., 1973. Frederick T. Knickerbocker: Oligopolistic Reaction and Multinational Enterprise, Graduate School of Business Administration, Harvard University, Boston, 1973. Stefan H. Robock and Kenneth Simmonds: International Business and Multinational Enterprises. Richard D. Irwin, Inc., Illinois, 1973. Enrique Yiloria: Empresa Multinacional. Integración Latinoamericana. Administración Pública, Comísión de Administración Pública, Caracas, septiembre 1973. Bureau of International Commerce: The Multinational Corporation, Studies on U.S. Foreign Investment, Volume I, U.S. Department of Commerce, march, 1972. Christopher Tugendhat: The Multinationals, Penguin Books, 1971. Raymond Vernon: Sovereignty at Bay: The Multinational Spread of U.S. Enterprises, Basic Books Inc., New York, London, 1971.

spatricia Wohlgemuth Blair: The Ministate Dilemma, Carnegie Endowment for International Peace, New York, 1968.

PPara Ia UNCTAD III, ver: Boletín Económico de América Latina, Naciones Unidas, Vol. XVII, N8 1, primer semestre de 1972. Para las Conferencias de los Países No Alineados, ver: Documentos de las Conferencias y Reuniones de los Países No Alineados, 1961-1973. Secretaría de Informaciones del Consejo Ejecutivo Federal, Belgrado, 1973. 
humano: la explosión demográfica y los problemas conexos de alimentación, educación, vivienda y empleo, característicos del mundo subdesarrollado ${ }^{10}$; la contaminación del medio ambiente ${ }^{11}$; la limitación de los recursos naturales ${ }^{12}$, y los peligros de una conflagración nuclear que podría aniquilar a la raza humana. ${ }^{13}$

\section{Los grandes interrogantes del futuro}

Es en este contexto que trataremos de analizar el contenido y el significado de los acuerdos firmados entre los Estados Unidos de América y la Unión de Repúblicas Socialistas Soviéticas, en Moscú (1972) y en Washington, D.C. (1973).

Porque, recuperando una vieja idea del apóstol San Pablo, hay que analizar el "kayrós" -el tiempo histórico "preñado de posibilidades" que describía con tanta agudeza Xavier Zubiri-14, y que en estos tiempos ofrece a nuestra generación un campo casi infinito para la acción, empezando por la propia naturaleza humana, hasta la construcción de nuevos elementos materiales; el descubrimiento de fuentes energéticas y la extensión de las fronteras del espacio humano hacia lugares ubicados fuera del planeta Tierra ${ }^{15}$. Las misiones Apolo a la Luna; el Skylab y la "expedición" al planeta Júpiter, son algunos ejemplos de lo que se expresa en el texto.

¿Qué actitud habrá que asumir frente al "kayrós" de nuestra generación? ¿Cómo adecuar nuestros pensamientos, nuestra manera de sentir y nuestros criterios de evaluación para una mejor comprensión de las circunstancias históricas y mundiales que nos rodean? ¿Podrá evitarse el que continuemos mirando a nuestro presente a través de un "espejo retrovisor" y el que pretendamos "avanzar hacia el futuro retrocediendo", según las gráficas expresiones de MacLu-

10Raúl Prebisch: Transformación y Desarrollo: La Gran Tarea de la América Latina, BID, FCE, México, 1970. CEPAL: El Cambio Social y la Politica de Desarrollo Social en América Latina, Naciones Unidas, Nueva York, 1969. Max F. Millikan: Una Estrategia para el Desarrollo, Centro de Información Económica y Social de las Naciones Unidas, Naciones Unidas, Nueva York, 1970.

${ }^{11}$ Harold W. Helfrich (editor): Agenda for Survival the Environmental Crisis, Yale University Press, New Haven-London, 1970. Garrett de Bell (editor): The Environmental Handbook, Ballantine Books, New York, 1970.

12Meadows et al.: The Limits to Growth, Universe Books, New York, 1972.

13Herman Kahn: On Thermonuclear War, Princeton, New Jersey, 1960.

1.4Xvier Zubiri: Naturaleza, Historia, Dios, Madrid, 1944. Para una referencia general a la obra de Zubiri, ver: Johannes Hirschberger: Historia de la Filosofía, Biblioteca Herder, Barcelona, 1970, Vol. II, pp. 513/515.

15Edgar Miles: International Administration of Space Exploration and Exploitation. The Social Science Foundation and Graduate School of International Studies, Monograph Series in World Affairs, University of Denver, Vol. 8, No 4, Denver, Colorado, 1970. 
Horacio II. Godoy / Los acuerdos entre los E.E. U.U. y la U.R.S.S.

han?16 ¿Cómo evaluar el significado y alcance de los acuerdos de Moscú y de Washington, D.C., desde el punto de vista de los países subdesarrollados? ¿Significa la "détente" y el relajamiento de las tensiones entre las superpotencias que no será necesaria una política especial para los países "no alineados"?, ¿o la "détente" sirve para reforzar el status quo internacional -un mundo de dos superpotencias y tres grandes potencias con el resto (más de 130) de países débiles- y en consecuencia, hacer aún más imperativa la necesidad por una política coordinada del Tercer Mundo? ${ }^{17}$

LA ESTRATIFICACIÓN EN TÉRMTNOS DEL PODER MUNDIAL

\section{El poder nuclear}

Las armas estratégicas de carácter ofensivo o fuerzas estratégicas nucleares están representadas por tres sistemas diferentes: los cohetes balísticos intercontinentales, basados en tierra o ICBMs, los cohetes balísticos lanzados desde el mar o SLBMs, y los bombarderos estratégicos. Existen también los llamados sistemas estratégicos defensivos formados por los anticohetes balísticos o ABMs que se complementan con los sistemas de alarma por satélites equipados con sensores infrarrojos dedicados a detectar las ojivas nucleares de los ICBM e informar al sistema anticohetes balísticos. Existen otros sistemas estratégicos defensivos en pleno desarrollo que se utilizarían contra los ataques de ICBM y de bombarderos estratégicos. ${ }^{18}$

- Aparte de las armas estratégicas nucleares de carácter ofensivo

${ }^{16}$ Marshall Me Luhan et al.: The Medium is the Massage, loc. cit., p. 75.

17Time, September 17, 1973, p. 7A, Welcome to the Third World.

18SIPRI (Stockholm International Peace Research Institute): World Armaments and Disarmaments, SIPRI Yearbook, 1972, Part I Strategic Nuclear Forces and SALT, Stockholm, Sweden, 1972, pp. 1/49. Ver además, para los antecedentes de SALT - Strategic Arms Limitation Talks - Conversaciones sobre Limitación de Armamentos Estratégicos - SIPRI Yearbook, 1969/1970, pp. 38/64. Pierre Hassner: SALT ou le triomphe de l'arms control, Revue Française de Science Politique, Volume XXIII, numéro 4, août, 1973, Presses Universitaires de France, pp. 779/789. Jean Pierre Derriennic: Les SALT et léquilibre nucléaire, loc. cit., pp. 790/800. Narie-France Toinet: Les Etats-Unis et les SALT ou comment désarmer sans désarmer, loc. cit., pp. 801/820. L'Union Soviétique et les SALT, loc. cit., pp. 821/842. Jean Kelin: Les SALT et la sécurité en Europe, loc. cit., pp. 843/858. Los armamentos estratégicos han creado una nueva terminología: ICBM (Intercontinental Ballistic Missiles) Proyectiles $\mathrm{Ba}$ lísticos Intercontinentales; SLBM (Sea-Launched Ballistic Missiles) Proyectiles Balísticos de Lanzamiento Submarino; $A B M$ (Anti-Ballistic Missiles) Proyectiles Anti-Balísticos. 
y defensivo, la capacidad del poder nuclear se mide en función de los siguientes criterios: a) según la cantidad del material explosivo nuclear; b) en función de la capacidad de precisión de los instrumentos que guían las cabezas nucleares para que alcancen su objetivo, de acuerdo con el criterio del "error circular probable" (CEP, Circular Error Probable), y c) por el número de cabezas nucleares que puedan ser transportadas por los diversos instrumentos o armamentos estratégicos. ${ }^{19}$

De acuerdo con los indicadores mencionados, los Estados Unidos y la Unión Soviética representan casi el $95 \%$ del poder estratégico nuclear en el mundo, y la estratificación internacional basada en el poder nuclear, presenta la forma de 2-3-18-120, es decir:

2 Superpotencias nucleares;

3 Potencias nucleares;

18 Países que podrán disponer de armas estratégicas dentro de los próximos diez años;

120 Países sin potencia nuclear.

A continuación se transcribe un cuadro con algunos de los datos disponibles sobre la existencia de las armas estratégicas, que se complementará con información sobre número de cabezas u ojivas nucleares almacenadas y el potencial nuclear medido en megatones. ${ }^{20}$

Estimación ACERCa DE LOS INSTRUMENTOS DE LANZAMIIENTO DE ARAMAS NUCLEARES 21

\begin{tabular}{|c|c|c|c|c|c|}
\hline & EE. UU. & U.R.S.S. & G. B. & Francia & China \\
\hline ICBMs con MIRVs $\ldots . \ldots$ & 150 & 1.520 & & & 420 \\
\hline $\sin$ MIRTS $_{\mathrm{S}}{ }^{a} \ldots \ldots$ & 904 & & & IRBM 9 & Varios \\
\hline Polaris SLBMIs MIRVs ..... & 544 & 400 & & & \\
\hline Poseidón SLBMs MIRVs ... & 112 & 100 & 64 & & \\
\hline $\begin{array}{l}\text { Bombarderos }(B-52 \text { y } F-I I l) \text {. } \\
\text { De largo alcance } \ldots \ldots \ldots \ldots \ldots\end{array}$ & 531 & I.40 & 56 & $36-60$ & 30 \\
\hline
\end{tabular}

- Multiple-individually - targetable-re-entry - vehicle.

Con respecto a las cabezas u ojivas nucleares ("warheads"), se han utilizado distintos procedimientos para determinar la cantidad probable acumulada por cada una de las superpotencias. Uno de los procedimientos consiste en dividir la cantidad estimada de material

19SIPRI Yearbook, 1969/1970, op. cit., pp. 39/40.

20 Un megatón es igual a un millón de toneladas de TNT. Si una bomba nuclear de un megatón es arrojada en una zona densamente poblada, puede aniquilar a un millón de personas. Un kilotón es igual a 1.000 toneladas de TNT.

21STPRI Yearbook; 1972, op. cit., p. 2. 
Horacio H. Godoy / Los acuerdos entre los E.E. U.U. y la U.R.S.S.

fisionable, por la cantidad requerida para fabricar una cabeza nuclear de 20 kilotones. Según este procedimiento, los Estados Unidos disponían en 1970 de unas 100.000 cabezas nucleares, de las cuales unas 7.000 estaban almacenadas en Europa Occidental. La Unión Soviética poseía en 1966 -según cálculos realizados por observadores de Europa Occidental debido a la ausencia de información de fuente soviética- entre 6.000 y 10.000 cabezas nucleares. Se ha estimado que el poder de la Unión Soviética en términos de cabezas nucleares ha sido siempre un porcentaje relativamente bajo del poder de los Estados Unidos, excepto en 1961 que se estimó en cerca de un $60 \%$ del total de cabezas nucleares de los Estados Unidos. Para tener una idea de las diferencias entre las superpotencias nucleares y las potencias nucleares, cabe mencionar que Gran Bretaña disponía en 1964 de unas 1.500 cabezas nucleares; Francia, de un centenar -no hay información precisa al respecto- y China, de algunas docenas de cabezas nucleares. ${ }^{2}$

Finalmente, otra medida de comparación del poder nuclear es la cantidad de explosivos nucleares medidos en megatones (1.000.000 de toneladas de TNT). El total de explosivo nuclear acumulado en el mundo es del orden de los 50.000 megatones, lo que representa cerca de 15 toneladas de TNT por persona en el mundo; la distribución per cápita aumenta a 60 toneladas de TNT si se limita a la población conjunta de los países miembros de la NATO y del Pacto de Varsovia ${ }^{23}$. Para tener una idea de la capacidad de muerte que tienen las armas estratégicas, cabe señalar que por cada megatón que cae en una ciudad populosa, morirían un millón de personas. ${ }^{24}$

El poder nuclear es una de las áreas de mayor concentración entre las grandes potencias, y responde a la tendencia que mencionamos anteriormente hacia la acumulación del poder en las dos superpotencias que acaban de firmar los Acuerdos de Moscú y de Washington, en 1972 y 1973 respectivamente.

\section{Otros indicadores de la estratificación internacional}

El análisis del producto interno bruto mundial para el año 1970 permite extraer algunas conclusiones que pueden ser útiles para una mejor comprensión de lo que significan los acuerdos entre las dos superpotencias nucleares. El cuadro siguiente da una idea bastante realista acerca de la estratificación internacional, comparando el

22SIPRI Yearbook, 1969/1970, op. cit., pp. 376/383.

23SIPRI Yearbook, 1969/1970, op. cit., p. 381.

24George W. Rathjens: The Future of the Strategic Arms Race. Options for the 1970 's, Garnegie Endowment for International Peace, New York, 1969, p. 44. 
producto interno bruto de los Estados Unidos y de la Unión de Repúblicas Socialistas Soviéticas con el producto bruto mundial $y$ con las demás regiones del mundo. ${ }^{2 \pi}$

Producto interno BRuto 1970

(Eslimado en dólares corrienles)

Total mundial

3.219 .255 .000 .000

Estados Unidos

974.100 .000 .000

U.R.S.S. 497.000 .000 .000

Tolal superpotencias

1.4 .71 .100 .000 .000

Europa (13 países miembros de la NATO) a 660.100 .000 .000

Europa (6 países miembros del Pacto de

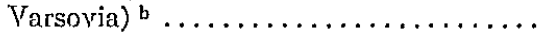

Otros países europeos " ............ 133.800.000.000

Tolal de Europa ....................

Asia (3I países del Cercano y del Lejano

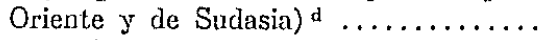

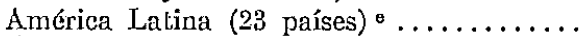

África $(34$ países) $f \ldots \ldots \ldots \ldots \ldots \ldots \ldots$

Oceanía $(2$ países) $8 \ldots \ldots \ldots \ldots \ldots \ldots \ldots$.

482.621 .000 .000

142.107 .000 .000

57.907 .000 .000

38.320 .000 .000

4 Excluye a los Estados Unidos y al Canadá. El P.I.B. de Canadá es de dólares 84.700.000.900.

b Excluye a la Unión Soviética. EI P.I.B. mús elevado corresponde a la República Democrática Alemana con dólares 32.300.000.000.

- Albania, Auptria, Finlandia, Trlanda, España, Suecia, Suiza y Yuzosiavia.

d Incluye a la China (República Popular), P.I.B. dblares 120.000.000.000 y Japón, P.I.B. dblares 197.180.000.000.

- Incluye a Gisyana, Jamaica y Trinidad-Tobago. Brasil (P.I.B. dólares 35.440.000.000) y iNéxico (P.I.B. dólares 33.000.000.000) representan los índices más elevados.

$t$ Incluye a Sud-África con P.I.B. dólares 16.690 .000 .000$.

* Australia y Nueva Zelandia. El P.I.B. de Australia asciende a dolares 32.990.000.000.

La observación del cuadro precedente, permite extraer las siguientes conclusiones:

1) El PIB de los Estados Unidos es casi el doble del de la Unión Soviética;

2) El PIB combinado de los Estados Unidos con el de la Unión Soviética, representa más del $45 \%$ del PIB mundial;

3) Las dos superpotencias tienen un PIB conjunto dos veces mayor que el PIB combinado de todos los países de Asia, Africa, América Latina y Oceanía;

4) América Latina representa, en términos de producto in-

25United States Arms Control and Disarmament Agency (ACDA): World Military Expenditures 1971, Bureau of Economic Affairs, Washington, D.C., 1972, pp. $22 / 25$. 
Horacio H. Godoy / Los acuerdos entre los E.E. U.U. y da U.R.S.S.

terno bruto, apenas el $10 \%$ del producto combinado de los Estados Unidos y de la Unión Soviética;

5) EI PIB de los Estados Unidos es superior al PIB combinado de todos los países de Europa (Occidental y Oriental);

6) El PIB de la Unión Soviética es superior al PIB de todos - los países del Asia, incluyendo a la República Popular China y al Japón;

7) El PIB de la Unión Soviética es dos veces mayor que el PIB combinado de América Latina, Africa y Oceanía;

8) EI PIB combinado de las cinco grandes potencias ubicadas después de las dos superpotencias -en orden decreciente- es inferior al PIB de los Estados Unidos, según lo demuestra el cuadro siguiente:

\section{Producto inthrno Bruto 1970}

(Estimado en dólares corrientes)

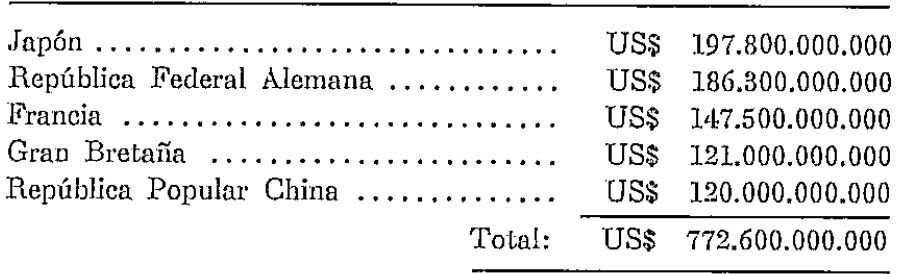

9) EI PIB de la Unión Soviética es superior al PIB combinado de Japón, República Popular China y Francia, y también superior al PIB combinado de la República Federal Alemana, Gran Bretaña y Francia;

10) La estratificación internacional, según el producto interno bruto, puede representarse en el cuadro siguiente:

\begin{tabular}{|c|c|c|c|}
\hline \multicolumn{3}{|c|}{$\begin{array}{l}\text { Miles de Millones } \\
\text { (Dolares 1970) }\end{array}$} & \multirow{2}{*}{$\begin{array}{r}\begin{array}{c}\text { Número } \\
\text { de } \\
\text { Países }\end{array} \\
\text {. I }\end{array}$} \\
\hline Más de 900.000 & & & \\
\hline$>>400.000$ & $\ldots \ldots \ldots \ldots \ldots \ldots$ & $\ldots \ldots$ & 1 \\
\hline$>100.000$ & y menos de 200.000 & & 5 \\
\hline$\gg 50.000$ & $\triangle \quad>1.00 .000$ & $\ldots \ldots$ & 3 \\
\hline$>\quad 20.000$ & > 50.000 & $\ldots \ldots \ldots \ldots \ldots \ldots$ & 14 \\
\hline$\gg \quad>10.000$ & > 20.000 & & 11 \\
\hline$\gg \quad 1.000$ & $\$ \quad 1.0 .000$ & $\ldots \ldots \ldots \ldots$ & 47 \\
\hline Menos de 1.000 & $\ldots \ldots \ldots \ldots \ldots \ldots$ & & 43 \\
\hline & & Total: & 125 \\
\hline
\end{tabular}


De los 1.25 países cuyo producto interno bruto se ha registrado en el estudio citado anteriormente, 90 países o sea el $71 \%$ del total de países estudiados tienen un producto interno bruto inferior a los 10.000 millones de dólares.

Complementa esta visión de la estratificación internacional del poder, el estudio de las grandes empresas transnacionales (Multinational Corporation) cuyas ventas anuales brutas son muchas veces superiores al producto interno bruto de muchos de los estados jurídicamente independientes. Así, por ejemplo, se han registrado 140 empresas transnacionales de los Estados Unidos cuyas ventas anuales brutas superan a los 1.000 millones de dólares. ${ }^{26}$

Un cuadro similar al anterior, pero referido a las empresas multinacionales dedicadas a la industria, da el siguiente resultado:

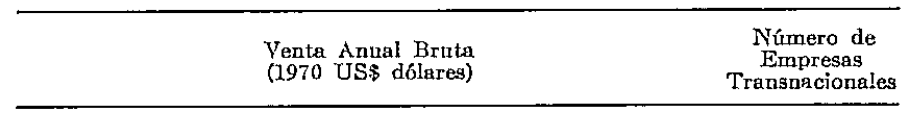

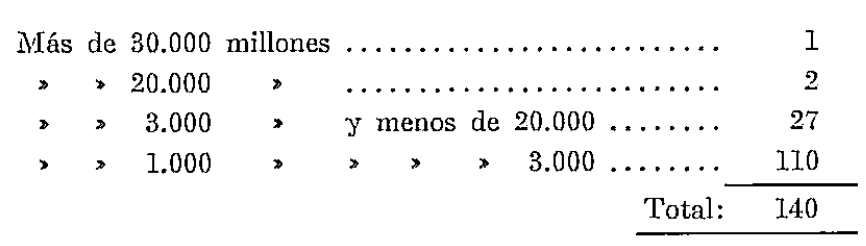

El total de ventas anuales brutas de las 140 empresas transnacionales que forman parte del "Club de los mil millones", asciende a unos 380.000 millones de dólares, lo que representa una cifra superior al PIB de todos los países del mundo, excepto los Estados Unidos y la Unión Soviética.

En una clasificación de los países y de las grandes empresas, en función del PIB y de las ventas anuales brutas, la General Motors aparece en el lugar $N^{9} 23$, inmediatamente después de la República Argentina. Este estudio se hizo en base a los datos correspondientes a $1970^{27}$. En 1972, la General Motors superó a la República Argentina en cifras comparadas y alcanzó al Brasil, al anotar u\$s 30.435.231.000 dólares en sus ventas anuales brutas ${ }^{28}$. Esta cifra es también superior al PIB sumado de los seis países integrantes del Grupo Andino.

Se incluyen en esta parte del trabajo las referencias a las em-

26Fortune: The Fortune Directory of the 500 Largest Industrial Corporations, May, 1973, pp. 220/247.

27Lester R. Brown: The Multinationals and the Nation-State, pp. 16-50/54, VISTA, June, 1973.

28Fortune Directory, op. cit. 
Horacio H. Godoy / Los acuerdos entre los E.E. U.U. y la U.R.S.S.

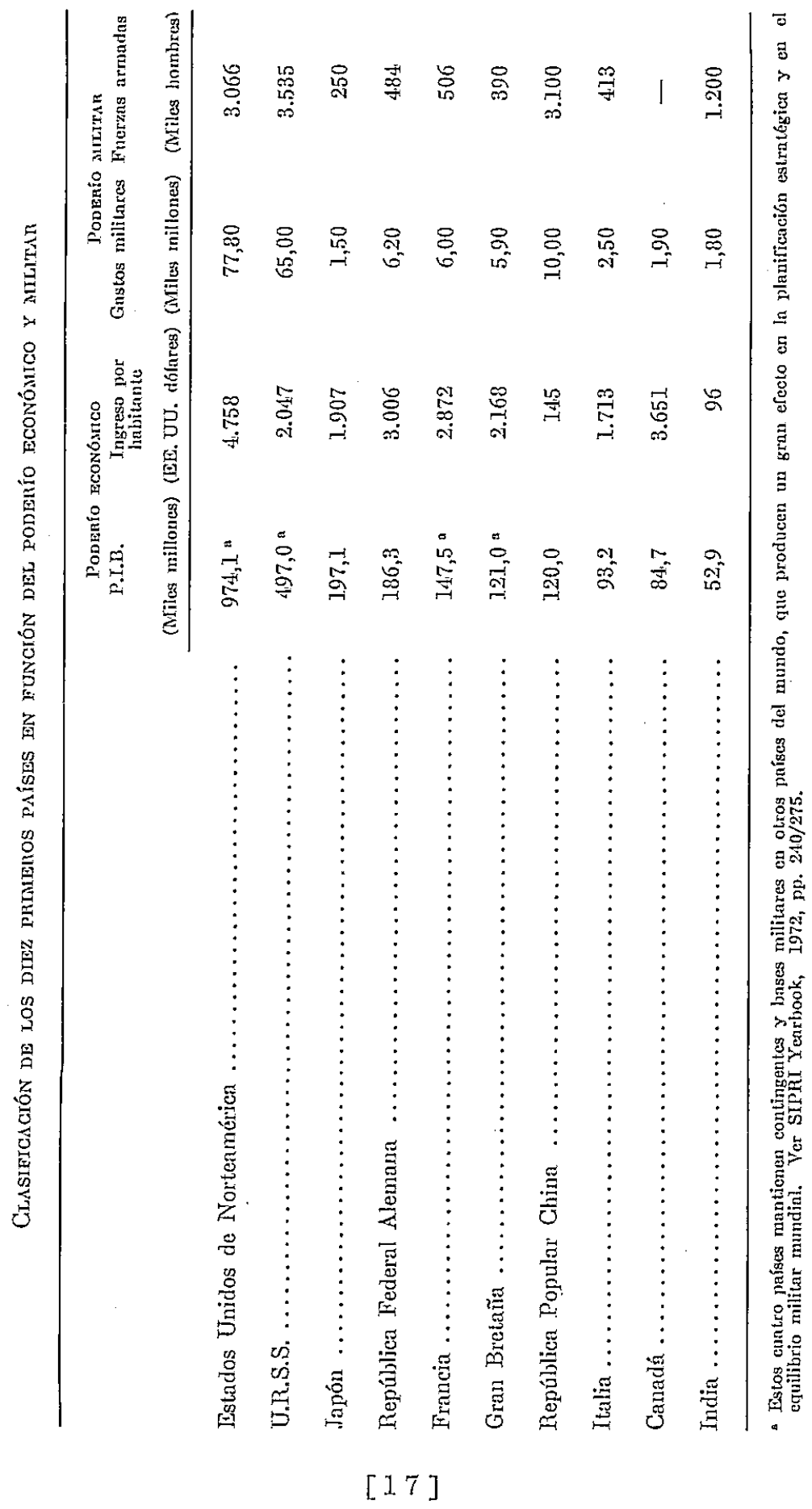


presas transnacionales, no sólo porque constituyen uno de los aspectos esenciales de la estructuración del poder mundial contemporáneo, sino porque los acuerdos en materia de comercio, celebrados entre la Unión Soviética y los Estados Unidos, regulan y estimulan el establecimiento de estas empresas en la Unión Soviética, fortaleciendo así el proceso de concentración del poder mundial. ${ }^{29}$

Para finalizar esta parte del trabajo, transcribiremos algunas informaciones comparativas militares y económicas para los 10 países, ubicados en la escala superior de la estratificación internacional. ${ }^{30}$

\section{Las altas partes contratantes}

Resulta imposible evaluar el significado de los Acuerdos de Moscú $y$ de Washington, D.C., sin tener una clara idea del potencial de cada una de las partes contratantes. Es la primera vez en la historia de la humanidad que existen dos superpoderes, dotados de capacidad para "sobrematar" (overkill capacity) y de realizar las proezas más extraordinarias en materia de exploración espacial. Y es la primera vez que estas dos superpotencias llegan a acuerdos, cuya importancia conceptuamos decisiva para el futuro de la humanidad. No en vano, las superpotencias que representan el $45 \%$ del producto mundial, el $95 \%$ del poder nuclear y otro tanto del poder espacial, han dado este histórico paso.

El señor Nikolai $\checkmark$. Podgorny, presidente del Presidium del Soviet Supremo de la Unión de Repúblicas Socialistas Soviéticas, dijo en Moscú, durante las ceremonias preparatorias de las negociaciones entre la Unión de Repúblicas Socialistas Soviéticas y los Estados Unidos, que "los resultados de las conversaciones determinarán por muchos conceptos las futuras relaciones entre los Estados Unidos y la Unión de Repúblicas Socialistas Soviéticas. Sus resultados, evidentemente, afectarán de alguna manera el desarrollo futuro de la situación internacional, orientándola sea hasta alguna paz más duradera y hacia una mayor seguridad universal, sea hacia una mayor tensión".

El presidente Nixon, por su parte, pudo decir, al iniciarse las negociaciones en Moscú, que "nos reunimos para inaugurar una nueva era en las relaciones de nuestras dos grandes y poderosas naciones", y agregó, "nunca dos pueblos han conocido compromiso

29Horacio H. Godoy: La Administración Pública, las Empresas Transnacionales y el Grupo Andino, ESAP, Bogotá, 1973, op. cit., y Multinational Corporations in World Development, United Nations, op. cit.

30ACDA: World Military Expenditure 1971, op. cit., p. 50. 
Horacio H. Godoy / Los acuerdos entre los E.E. U.U. y la U.R.S.S.

más grande, ni tenido más elevadas metas. Seamos dignos de las esperanzas del pueblo soviético, del pueblo norteamericano, y de todos los pueblos de la tierra, al trabajar juntos por la meta de la paz mundial". ${ }^{31}$

¿Qué tipo de relaciones internacionales entre las dos superpotencias regulan Ios Acuerdos de Moscú y de Washington? ¿Cuál es el significado de estos Acuerdos para los Estados Unidos, para la Unión Soviética y para los demás países del planeta? ¿Serán estos tratados el comienzo de una nueva era en la historia de las relaciones internacionales y de la política mundial? ¿O constituirán un medio para afianzar el status quo de países dominantes y países dominados? ¿Se extenderán los beneficios de las políticas que inspiran estos Acuerdos entre las superpotencias hacia el mundo subdesarrollado?

En las próximas páginas, trataremos de responder a estos interrogantes.

EL CONTENIDO DE LOS ACUERDOS ENTRE LOS ESTADOS UNIDOS DE AMÉRICA Y LA UNIÓN DE REPÚBLICAS SOCIALISTAS SOVIÉTICAS

Los Acuerdos de Moscú (1972)

Entre los días 22 y 30 de mayo de 1.972, el presidente de los Estados Unidos de América, Richard Nixon, realizó una histórica visita a la Unión Soviética durante la cual se firmaron seis convenios bilaterales sobre:

1) la protección del medio;

2) la ciencia médica y la salud;

3) la cooperación espacial;

4) la ciencia y la técnica;

5) Ia prevención de incidentes marítimos; y

6) las relaciones comerciales.

Además, se firmó el Tratado sobre la limitación de los armamentos estratégicos y un Acuerdo Provisional, y se definieron los Principios Básicos de las Relaciones entre los Estados Unidos de América y la Unión de Repúblicas Socialistas Soviéticas. ${ }^{32}$

31 El Presidente Nixon en Moscú (Resumen de las Declaraciones y los principales acuerdos logrados durante la visita del Presidente Nixon a la Unión Soviética, del 22 al 30 de mayo de 1972), Servicio de Información de los Estados Unidos, pp. $1 / 3$.

32Para la elaboración de esta parte del trabajo, se han consultado las docu- 
El cuadro de págs. 21-23 intenta resumir los aspectos más importantes de los Acuerdos mencionados.

Los Principios Básicos de las relaciones entre los Estados Unidos de América y la Unión de Repriblicas Socialistas Soviéticas (Mos$c u$, 1972)

Uno de los documentos más interesantes, firmados en la reunión de Moscú, fue el que se refiere a los "Principios Básicos" que orientarán las relaciones entre los Estados Unidos y la Unión de Repúblicas Socialistas Soviéticas.

Estos Principios tienen como propósito fundamental "hacer todo esfuerzo para eliminar la amenaza de guerra y crear las condiciones que propicien la reducción de las tensiones en el mundo $\mathrm{y}$ el fortalecimiento de la seguridad universal y la cooperación internacional" (segundo considerando de los Principios Básicos).

Los doce Principios pueden reducirse a seis temas o áreas principales.

1. Un principio general, que resulta del reconocimiento explícito de las nuevas exigencias impuestas por la era nuclear: "en la era nuclear, no hay más alternativa (para los Estados Unidos y la Unión de Repúblicas Socialistas Soviéticas) que llevar sus relaciones mutuas sobre la base de la coexistencia pacífica". Y se expresa en forma terminante que "las diferencias de ideología y de sistemas sociales de los Estados Unidos y de la Unión de Repúblicas Socialistas Soviéticas no constituyen un obstáculo a la ayuda bilateral de relaciones normales, basadas en los principios de soberanía, igualdad, no intervención en los asuntos internos y beneficio mutuo" (Principio primero).

2. Principios que se refieren a la paz mundial, entendida como la ausencia de confrontaciones militares y prevención de la guerra nuclear. Los Principios segundo y tercero se refieren a estos temas, mencionando expresamente la responsabilidad conjunta de las superpotencias con los demás países miembros

mentaciones oficiales de las reuniones, publicadas por el Servicio de Información de los Estados Unidos y por la Editorial de la Agencia de Prensa Nóvosti, Moscú. La publicación titulada, El Presidente Nixon en Moscú, Resumen de las declaraciones y principales acuerdos logrados durante la visita del Presidente Nixon a la Unión Soviética del 22 al 30 de mayo de 1972, fue realizada por el Servicio de Información de los Estados Unidos y la publicación: URSS: El Programa de Paz en Acción, por la Editorial de la Agencia de Prensa Nóvosti. El autor agradece a las embajadas de los Estados Unidos y de la Unión Soviética en Colombia, por la entrega de esa valiosa documentación. 
Horacio H. Godoy / Los acuerdos entre los E.E. U.U. y la U.R.S.S.

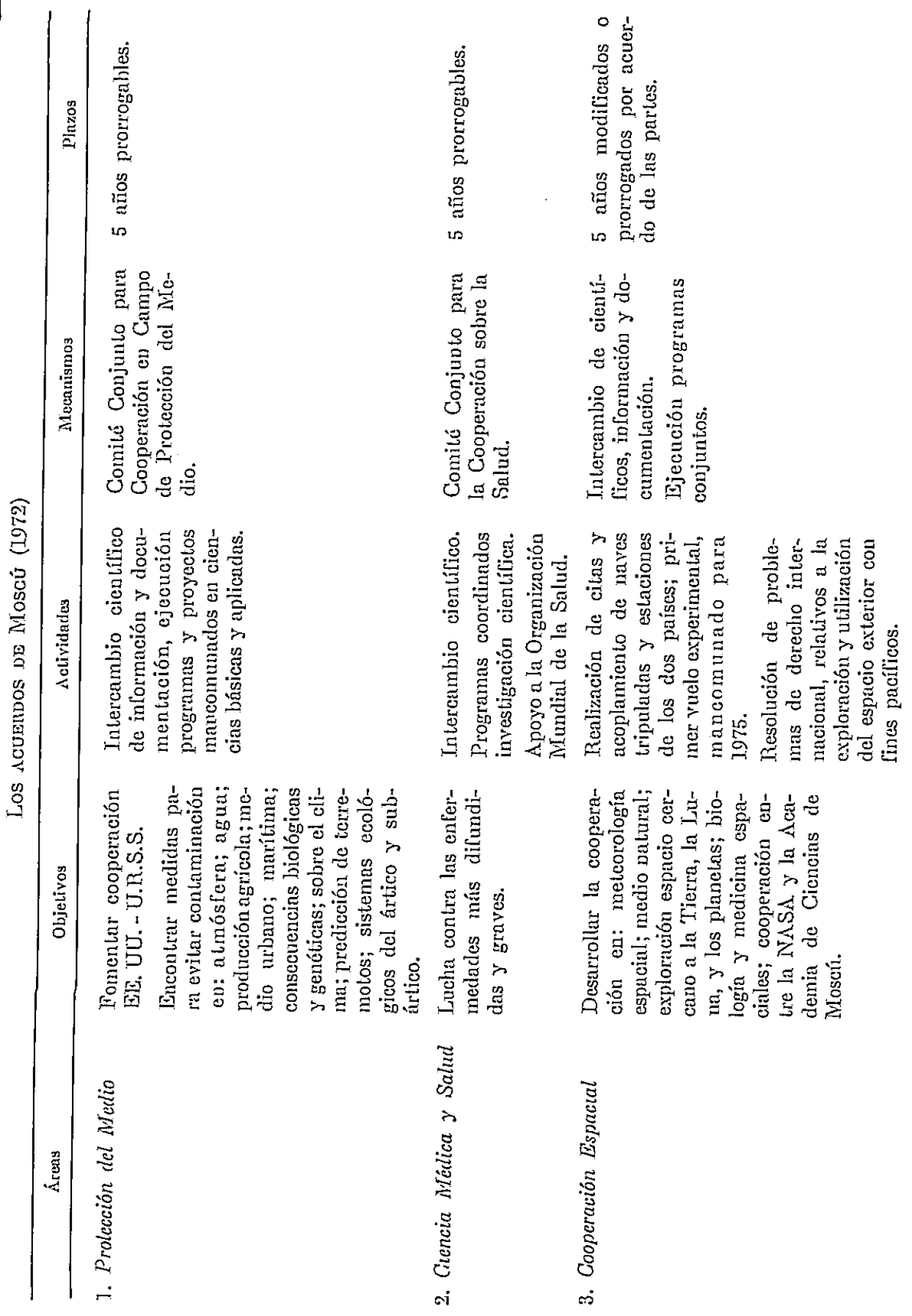


ESTUDIOS INTERNACIONALES

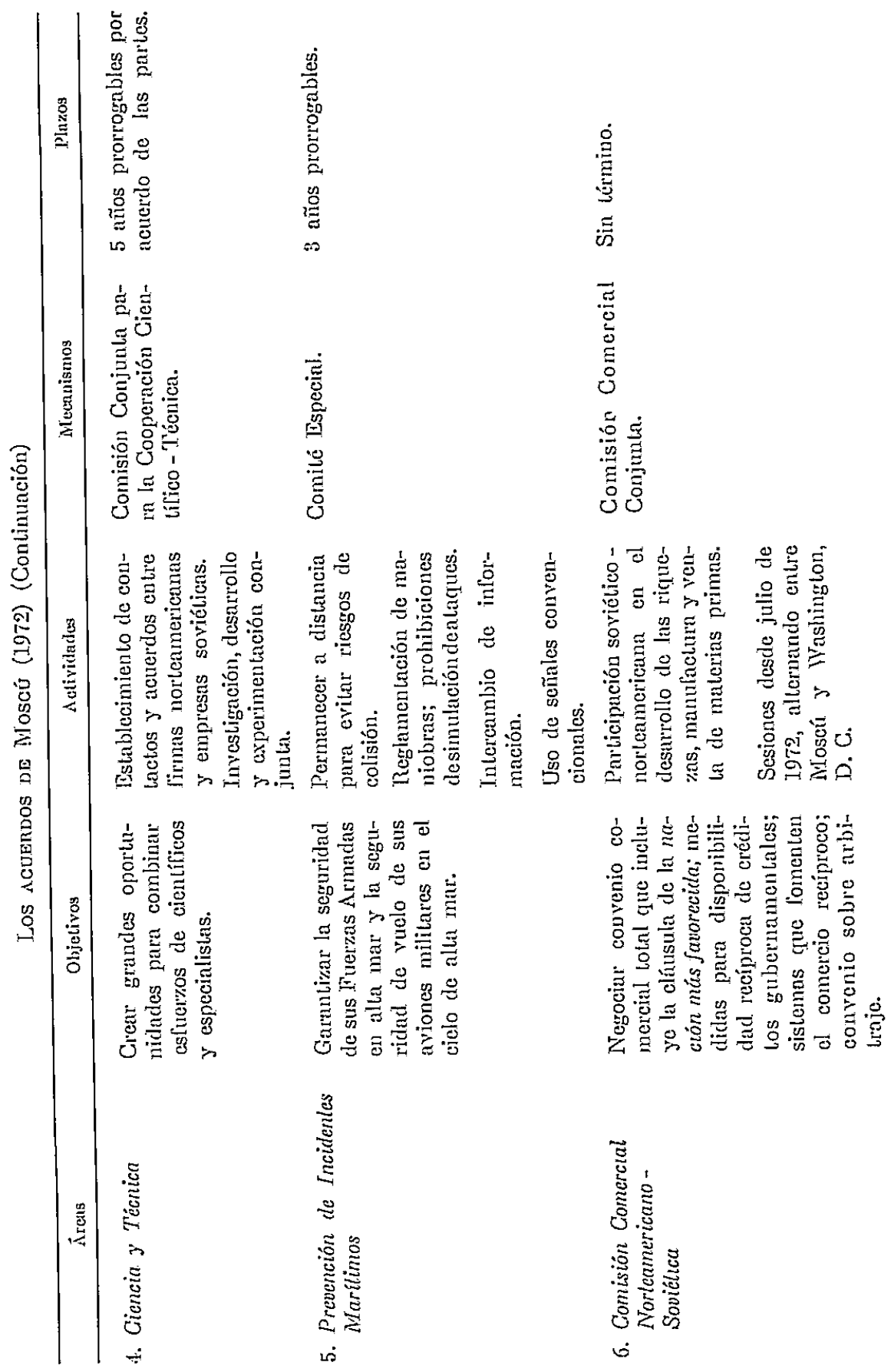


Horacio H. Godoy / Los acuerdos entre los E.E. U.U. y la U.R.S.S.

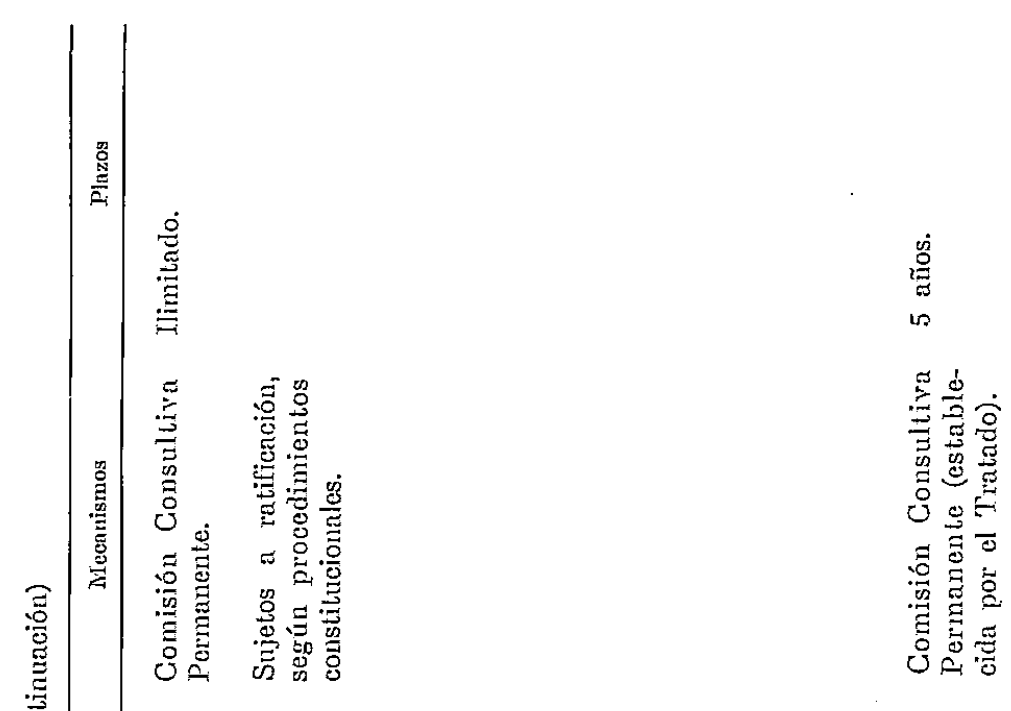

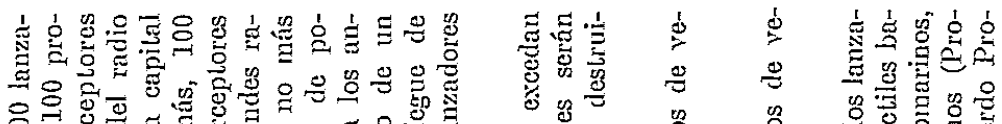

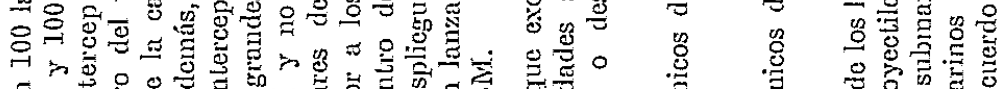

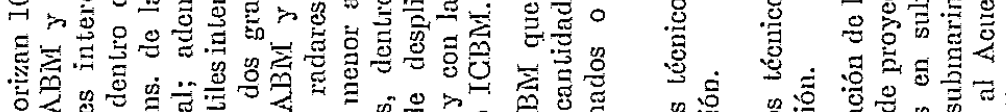

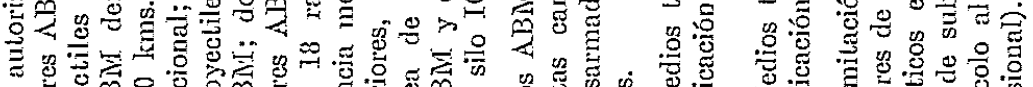

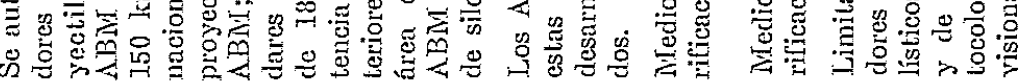

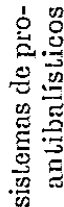

仓’

药

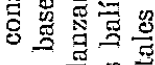

范嵒要

氙䆑

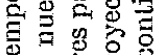

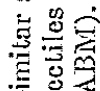

ज㛡

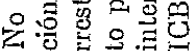
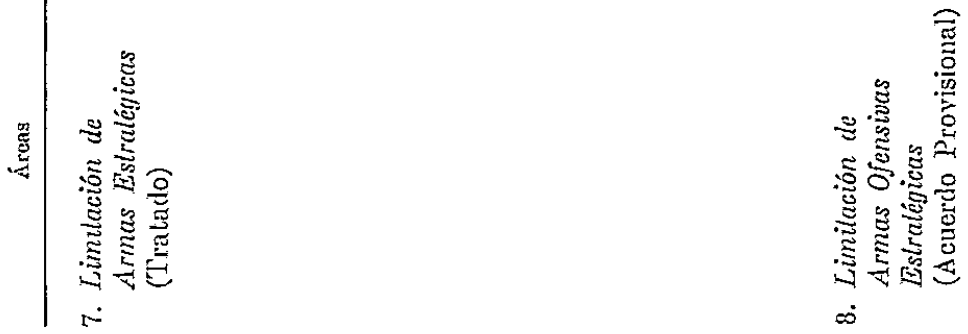
permanentes del Consejo de Seguridad de las Naciones Unidas. En este mismo tema, el Principio sexto trata de la limitación de armamentos, empezando por las armas estratégicas, para alcanzar el desarme general y total y, muy especialmente, el "establecimiento de un sistema efectivo de seguridad internacional de acuerdo con los propósitos y los principios de las Naciones Unidas".

3. Principios que se refieren a las bases jurídicas e institucionales. EI Principio cuarto dice que los Estados Unidos y la Unión de Repúblicas Socialistas Soviéticas "intentan ampliar la base jurídica de sus relaciones mutuas", y el Principio décimo se refiere a la necesidad de que sus vínculos y los acuerdos de cooperación se "asienten sobre bases firmes y duraderas", para lo cual propone la creación de "comisiones u otros cuerpos conjuntos". Para fortalecer las instituciones jurídicas y el funcionamiento de las comisiones conjuntas, el Principio quinto estimula los procedimientos de intercambio de opiniones en todos los niveles.

4. Principios que regulan las relaciones económicas y comerciales. Las relaciones económicas y comerciales, son consideradas como "importantes y necesarias" para el fortalecimiento de las relaciones bilaterales. Por tal motivo, fomentarán y facilitarán "la cooperación entre las organizaciones y las empresas, destacadas de ambos países, lo mismo que la conclusión de convenios y contratos apropiados, incluso a largo plazo".

Este Principio séptimo confirma lo que ya se había regulado a través del Acuerdo sobre Cooperación en los Campos de la Ciencia y de la Técnica, que acababa de firmarse durante las reuniones de Moscú. En efecto, el artículo 3, letra f), dice textualmente: "Prestación de la ayuda apropiada por ambas partes para el establecimiento de contactos y acuerdos entre firmas norteamericanas y empresas soviéticas acerca de las cuales exista un interés común"; y el artículo 4, dispone que de conformidad con los propósitos del Convenio sobre Cooperación en Ciencia y Técnica, las partes "alentarán y facilitarán el establecimiento y el desarrollo de contactos y de cooperación directos entre dependencias, organizaciones y firmas de uno y otros países". Éste párrafo del artículo 4 continúa expresando: “así como la conclusión, como es conveniente, de los acuerdos de ejecución de actividades particulares de cooperación, emprendidas con base en este convenio". Esta es la versión norteamericana (página 7). En la versión rusa (página 33), este párrafo se expresa: "así como la conclusión de los correspondientes acuerdos de trabajo para actividades conjuntas a realizar en el 
marco del presente convenio". ¿Por qué estas diferencias conceptuales? ¿Se trata de un simple error en la traducción? ¿O es diferencia de énfasis en lo que, para los Estados Unidos, son actividades particulares, es decir, de sus empresas privadas, mientras que para la Unión de Repúblicas Socialistas Soviéticas son sólo actividades conjuntas entre sus "organizaciones y dependencias" y las firmas norteamericanas?

El párrafo 2 del artículo 4 del Convenio de Cooperación en Ciencia y Técnica dispone que "los acuerdos entre dependencias, organizaciones y empresas serán concluidos de acuerdo con las leyes de ambas naciones". Se introduce más claramente la noción de empresa (empresa privada norteamericana), que es sinónimo de firma. Cada organización, dependencia o empresa participante, en acuerdos de ejecución, sufragará los gastos de su participación y la de su personal, salvo que se especifique otra cosa en los respectivos acuerdos de ejecución (artículo 5).

Una Comisión Conjunta Norteamericano-Soviética para la Cooperación Científica y Técnica tendrá a su cargo la consideración de las propuestas para el desarrollo de la cooperación "en terrenos específicos"; la preparación de sugerencias y recomendaciones pertinentes a las dos partes; determinará y aprobará las medidas y programas para la ejecución del presente Convenio; y "designará, como conviene, las dependencias, organizaciones y empresas responsables de desempeñar actividades de cooperación, e intentará garantizar su debida ejecución".

El cumplimiento de este Convenio se garantiza a través de la Oficina de Ciencia y Técnica del Departamento Ejecutivo de la Presidencia de los Estados Unidos y a través del Comité Estatal del Consejo. Soviético de Ministros para la Ciencia y la Técnica, de la Unión de Repúblicas Socialistas Soviéticas (artículo 7, No 3 ).

Hemos creído conveniente transcribir con más detalles, las disposiciones del Convenio de Cooperación en Ciencia y Técnica, porque es el documento en el que se regulan con mayor claridad las relaciones entre las "organizaciones y dependencias" de la Unión de Repúblicas Socialistas Soviéticas y las firmas o empresas privadas norteamericanas. $Y$ es interesante destacar que la vía por la cual se regulan estas importantes relaciones entre las dos superpotencias es la de la cooperación científica y técnica, es decir, la de la transferencia de tecnología para aplicarla a los más diversos sectores de actividad o "terrenos específicos", como expresa el artículo 7, № 2. 
5. Principios que se refieren a la ciencia y la técnica, y a la cultura. El Principio nctavo considera "oportuno y conveniente" fomentar los contactos y la cooperación mutua en los campos de la ciencia y de la téznica y expresa con cierta candidez: "Cuando sea adecuado, los Estados Unidos y la Unión de Repúblicas Socialistas Soviéticas concluirán convenios apropiados acerca de la cooperación concreta en esos campos".

Este párrafo resulta sorprendente por dos motivos. En primer lugar, por la debilidad de sus expresiones, en un sector de actividad que parecería tener importancia primordial en la era nuclear. Apenas se considera "oportuno y conveniente". Los Principios que se refieren al sector económico y comercial consideran a este sector "importante y necesario". Pero, en segundo lugar, sorprende que se diga que "cuando sea adecuado se firmarán convenios acerca de cooperación concreta en estos campos", dejando de lado el más detallado Convenio de Cooperación en el Campo de la Ciencia y de la Técnica, firmado cinco días antes de los Principios Básicos. Este hecho reafirma la interpretación del Convenio de Cooperación en la Ciencia y en la Técnica, como un convenio principalmente orientado a regular las relaciones de las "organizaciones y dependencias" oficiales soviéticas con las firmas o empresas privadas norteamericanas en el campo de la transferencia o comercialización de la tecnología.

6. El contexto mundial de los Acuerdos está contemplado en los Principios undécimo y duodécimo. Estos Principios tienen una importancia extraordinaria, como instrumentos de análisis de la realidad mundial contemporánea. El Principio undécimo dice: "Los Estados Unidos y la Unión de Repúblicas Socialistas Soviéticas no reclaman para sí ninguna clase de derechos o ventajas especiales en los asuntos mundiales, ni reconocerán las pretensiones de cualquier otro país a tales derechos y ventajas. Ambos reconocen la igualdad soberana de todas las naciones. El desarrollo de las relaciones entre los Estados Unidos y la Unión de Repúblicas Socialistas Soviéticas no va dirigida contra terceros países ni contra sus intereses".

Este Principio contiene tres aspectos principales:

a) la declaración formal de los Estados Unidos y de la Unión de Repúblicas Socialistas Soviéticas, en el sentido de que no reclaman ningún derecho ni ventaja en asuntos mundiales;

b) la afirmación de que no reconocerán las pretensiones que en este sentido tengan otros países; y 
c) la expresión de que la política de entendimiento entre los Estados Unidos y la Unión de Repúblicas Socialistas Soviéticas ("el desarrollo de las relaciones") no se dirige contra terceros países, ni contra sus intereses.

Los aspectos mencionados en las letras a) y b) son, o bien una repetición redundante de los principios del derecho internacional y de la Carta de las Naciones Unidas, a la que dejan de lado; o bien una manera muy elemental de tratar de calmar las preocupaciones de los 140 "terceros países" ante los Acuerdos de las dos superpotencias. En cuanto a la aclaración sobre el sentido de la política de entendimiento entre los Estados Unidos y la Unión de Repúblicas Socialistas Soviéticas, manifestando que no se dirige contra terceros países, aparece como una constante preocupación de los máximos dirigentes soviéticos. En el tercer considerando de los Principios Básicos, se afirma que "el mejoramiento de las relaciones entre los Estados Unidos, así como su desarrollo mutuamente benéfico en campos como la economía, la ciencia y la cultura, servirán para alcanzar esas metas y contribuirán a un mejor entendimiento mutuo y a una mayor cooperación de tipo comercial, sin perjudicar en manera alguna los intereses de terceros países".

La Unión de Repúblicas Socialistas Soviéticas ha sido terminante en sus expresiones sobre el alcance de los Acuerdos, respecto de terceros países. "La Unión Soviética estima posible y deseable el establecimiento de relaciones, no sólo buenas, sino amistosas entre la URSS y los EE. UU,, naturalmente, siempre que no sea a expensas de otras naciones o de otros pueblos" (Nikolai V. Podgorny en la inauguración de las reuniones de Moscú). "De poco servirían las decisiones sobre las que hemos estado de acuerdo o sobre las que podríamos estarlo si se opusieran a los legitimos intereses de otras naciones, a los intereses de su seguridad y su independencia. No nos reunimos con el señor presidente de los Estados Unidos ante la mesa de conferencias para decidir por otros pueblos y otras naciones" (Alexei N. Kosygin, al finalizar las reuniones de Moscú).

Aunque habrá que interpretar estas declaraciones en función del comportamiento efectivo de las dos superpotencias, no puede dudarse de la importancia fundamental que tienen para los terceros países, que quieren ver en el respeto declarado de las superpotencias por sus legítimos intereses, las bases para una efectiva y más amplia participación en la construcción del orden mundial del siglo $\mathrm{xxx}$. 
El Acuerdo sobre Comercio entre la Unión de Repúblicas Socialistas Soviéticas y los Estados Unidos, firmado en octubre de 1.972

Uno de los Acuerdos logrados en Moscú fue el que se refiere a la necesidad de regular las relaciones comerciales entre las superpotencias. En un comunicado conjunto de fecha 26 de mayo de 1972 , los dirigentes soviéticos y norteamericanos acordaron establecer una Comisión Comercial Norteamericano-Soviética. Esta Comisión Comercial mixta tenía por objetivos, entre otros, el de negociar "un convenio comercial total que incluye el tratamiento recíproco de nación más favorecida" (NMF).

En octubre de 1.972, las dos superpotencias firmaron el Acuerdo sobre Comercio, estableciendo así las bases para un intenso y muy variado intercambio entre los Estados Unidos y la Unión de Repúblicas Socialistas Soviéticas.

Como parte del Acuerdo, Ia Unión de Repúblicas Socialistas Soviéticas aceptó pagar a los Estados Unidos la deuda proveniente del sistema de préstamos y arriendos de la Segunda Guerra Mundial por valor de 722 millones de dólares. La forma de pago convenida permitirá a la Unión de Repúblicas Socialistas Soviéticas pagar su deuda total en el año 2001..33

El Acuerdo sobre Comercio establece la cláusula recíproca de la nación más favorecida (NMF), que deberá ser aprobada por el Congreso de los Estados Unidos, y que actualmente está pendiente de la resolución que el Senado de los Estados Unidos adopte sobre una enmienda, presentada por el senador Jackson, en el sentido de no acordar el beneficio de nación más favorecida en las relaciones comerciales con la Unión Soviética, mientras en ese país se mantenga el régimen que prohíbe la emigración de judíos desde la Unión de Repúblicas Socialistas Soviéticas. ${ }^{34}$

EI Acuerdo contempla también la concesión de créditos comerciales y la construcción de un edificio adecuado para alojar a miembros permanentes o visitantes de grupos de comerciantes, en Washington y en Moscú.

33 Time, October 10, 1972, p. 43.

34Time: What's Price the Jackson Amendment?, October 1, 1973, pp. 35/36. Esta propuesta del senador Jackson encuentra también apoyo en una de las figuras más controvertidas en la Unión Soviética: el sabio físico nuclear Andrei Sakharov, quien sostiene que "hay decenas de miles de ciudadanos que desean salir de la Unión Soviética ... Ústedes conocen que las prisiones, campos de trabajo y sanatorios mentales están repletos de gente que ha tratado de ejercer este derecho legítimo. Yo apelo al Congreso de los Éstados Unidos para dar apoyo a la enmienda Jackson". Estos son los términos de una carta enviada por Andrei Sakharov al Congreso de los Estados Unidos, según la versión citada de Time. 
Horacio H. Godoy / Los acuerdos entre los E.E. U.U. y Ja U.R.S.S.

Este Acuerdo sobre Comercio constituye la base para un plan de gran expansión del intercambio entre la Unión Soviética y los Estados Unidos, que actualmente alcanza apenas a unos 200 millones de dólares. Según declaraciones de dirigentes soviéticos y norteamericanos, la idea es aumentar el intercambio a 2 y 3 mil millones de dólares hacia el final de la década. Leonidas I. Brézhnev ha hablado de llegar a los 250.000 millones de dólares de intercambio comercial en los próximos 20 años. $^{35}$

\section{Los Acuerdos de Washington, D.C. (1973)}

Durante los días 18 al 25 de junio del corriente año 1973, el secretario general del Comité Central del Partido Comunista de la Unión Soviética, Leonidas I. Brézhnev, visitó a los Estados Unidos y firmó varios acuerdos con el presidente Richard Nixon sobre las siguientes materias: ${ }^{36}$

1. Agricultura

2. Investigación del Océano Mundial

3. Transporte

4. Contactos, intercambio y colaboración entre la URSS y los EE. UU.

5. Tributación

6. Energía atómica con fines pacíficos

7. Armamentos estratégicos ofensivos

8. Prevención de la guerra nuclear

9. Representaciones comerciales de la URSS en Washington y de los EE. UU. en Moscú

10. Cámara de Comercio Norteamericano-Soviética.

35Time: And Now, Moscow's Dollar Diplomat, June 25, 1973, pp. 6/13. Sostiene el editorial de Time que posiblemente se trate de "una era de détente que evoluciona hacia una época de diplomacia comercialmente orientada por el dólar y el rublo", p. 6. La suma de dólares 250 mil millones parece poco realista. En 1972 el comercio entre los Estados Unidos y la Unión de Repúblicas Socialistas Soviéticas ascendió a 642,1 millones de dólares, pero se debió principalmente a las ventas de cereales de los Estados Unidos a la Unión Soviética. Un comité del Congreso de los Estados Unidos ha estimado que el comercio soviético-norteamericano ascenderá hasta 5 mil millones de dólares anuales hacia el fin de la década. Para dar una idea aproximada del valor relativo de estas estimaciones, hay que tener presente que el comercio de los Estados Unidos con Europa Occidental fue de $30 \mathrm{mil}$ millones en 1972 y con Japón llegó a $14 \mathrm{mil}$ millones. Time, loc. cit., p. 10.

36Para esta parte del trabajo he revisado los documentos siguientes: Conversaciones URSS-EE.UU., Documentos, Junio, 1973. Editorial de la Agencia de Prensa Novosti, Noscú, 1973, y The Washington Summit: General Secretary Brezhnev's Visit to the United States, June 18-25, 1973. Department of State Publication 8733, Office of Media Services, Bureau of Public Affairs, August, 1973, Ver nota 31 . 
Los Acuerdos de Washington son, o bien una ampliación o extensión de las áreas, consideradas por los Convenios de Moscú, o bien la introducción de áreas uuevas. En todo caso, hay que tener presente que, después de un año transcurrido desde las reuniones de Moscú, en mayo de 1972 , los líderes máximos de las superpotencias vuelven a reunirse -esta vez en Washington, D.C.- y al firmar un conjunto de nuevos acuerdos, ratifican el espíritu de colaboración y de fortalecimiento y expansión de las relaciones entre los Estados Unidos y la Unión Soviética. Este espíritu quedó claramente expresado en el Comunicado Conjunto Soviético-Norteamericano publicado al final de las reuniones de Washington. En este Comunicado, se reconoce que "el proceso de reestructuración de las relaciones soviético-norteamericanas" ... "transcurre exitosamente". ${ }^{3 \tau}$

Las reuniones de Washington incluyen dos hechos de especial significación: la entrevista del secretario general, Leonidas I. Brézhnev, con los miembros de la Comisión Senatorial para Asuntos Exteriores del Congreso de los Estados Unidos, el 19 de junio de 1973, y la entrevista con los representantes del mundo de los negocios de los Estados Unidos, el 22 de junio del mismo año. En el capítulo correspondiente a las interpretaciones de los Acuerdos de Moscú y de Washington, se analizarán las expresiones del secretario general, Leonidas I. Brézhnev, con ocasión de esas entrevistas. Basta consignar acá el contacto oficial del dirigente soviético con la Comisión de Relaciones Exteriores del Senado, uno de los más fuertes centros de poder para la definición de las relaciones exteriores de los Estados Unidos, especialmente importante para la ratificación de algunos tratados de la Unión Soviética y los Estados Unidos, como por ejemplo, el que se refiere a la limitación de los armamentos estratégicos y la convención sobre cuestiones de tributación.

En cuanto a la reunión con representantes del mundo de los negocios, consideramos que es una de las más espectaculares de nuestro tiempo, no sólo por el tipo de reunión y su innegable efecto de demostración que tendrá en otras áreas del mundo, sino por la forma franca y magistral en que el secretario general, Leonidas I. Brézhnev, trató el tema de la colaboración de la empresa privada norteamericana con las organizaciones y dependencias especializadas de la Unión Soviética. Al referirse a las relaciones económicas entre la Unión Soviética y los Estados Unidos, dijo que "criticamos con aspereza a muchos de nuestros departamentos que se ocupan de tales asuntos por lo reducida que es la escala de sus actividades, por su timidez, por sus nociones caducas, por las insuficiencias en

37Conversaciones URSS-EE.UU., Documentos, op. cit., p. 6. 
su trabajo. Pero, con la misma franqueza, quisiera criticar aquí, frente a frente, a los empresarios norteamericanos - a quienes desde los tiempos de V. I. Lenin estimamos precisamente por su diligencia-, criticarlos porque en ocasiones no revelan la audacia debida, no operan en la escala debida, viven cautivos de nociones anticuadas". 38

Para dar una idea panorámica de los Acuerdos, firmados en Washington, D.C., se transcribe un cuadro sintético de dichos Acuerdos, consignando el área del Acuerdo, sus objetivos, actividades, mecanismos y plazos (pp. 32-35).

Las reuniones de Washington, D.C., marcan un avance extraordinario en el llamado proceso de reconstrucción de las relaciones entre la Unión Soviética y los Estados Unidos, no sólo por la extensión del número de los Acuerdos, que ascienden a 18 convenios, tratados y protocolos, sino por la vinculación directa del gobierno de la Unión de Repúblicas Socialistas Soviéticas con la empresa transnacional privada de origen norteamericano. En la entrevista que Leonidas I. Brézhnev tuvo con los representantes del mundo de los negocios, estuvieron presentes, entre otros, representantes de las siguientes firmas:

\author{
Bank of America \\ First National City Bank \\ Chasse Manhattan Bank \\ General Motors Corporation \\ General Electric Company \\ US Steel Corporation \\ International Business Machine \\ Dupont (E.I.) de Nemours and Company \\ EXXON \\ El Paso Natural Gas Company \\ Occidental Petroleum Corporation \\ Swindell Dressel Company \\ Boeing Company \\ Pepsico Incorporated.
}

En esa entrevista, Leonidas I. Brézhnev dijo que "sería cosa anormal que suscribiéramos un acuerdo referente a la articulación de nuestras relaciones, conforme a los principios de la coexistencia pacífica, sin fomentar a la vez el comercio y los vínculos económicos de nuestros países". ${ }^{39}$

38Leonidas I. Brézhnev: Entrevistas de Leonidas I. Brézhnev con los Representantes del Mundo de los Negocios, 22 de Junio, 1973, en: "Nuestro Rumbo: La Paz y el Socialismo", Segunda parte, Moscú, 1973, pp. 16/21.

39Leonidas I. Brézhnev: loc. cit., p. 17. 
ESTUDIOS INTERNACIONALES

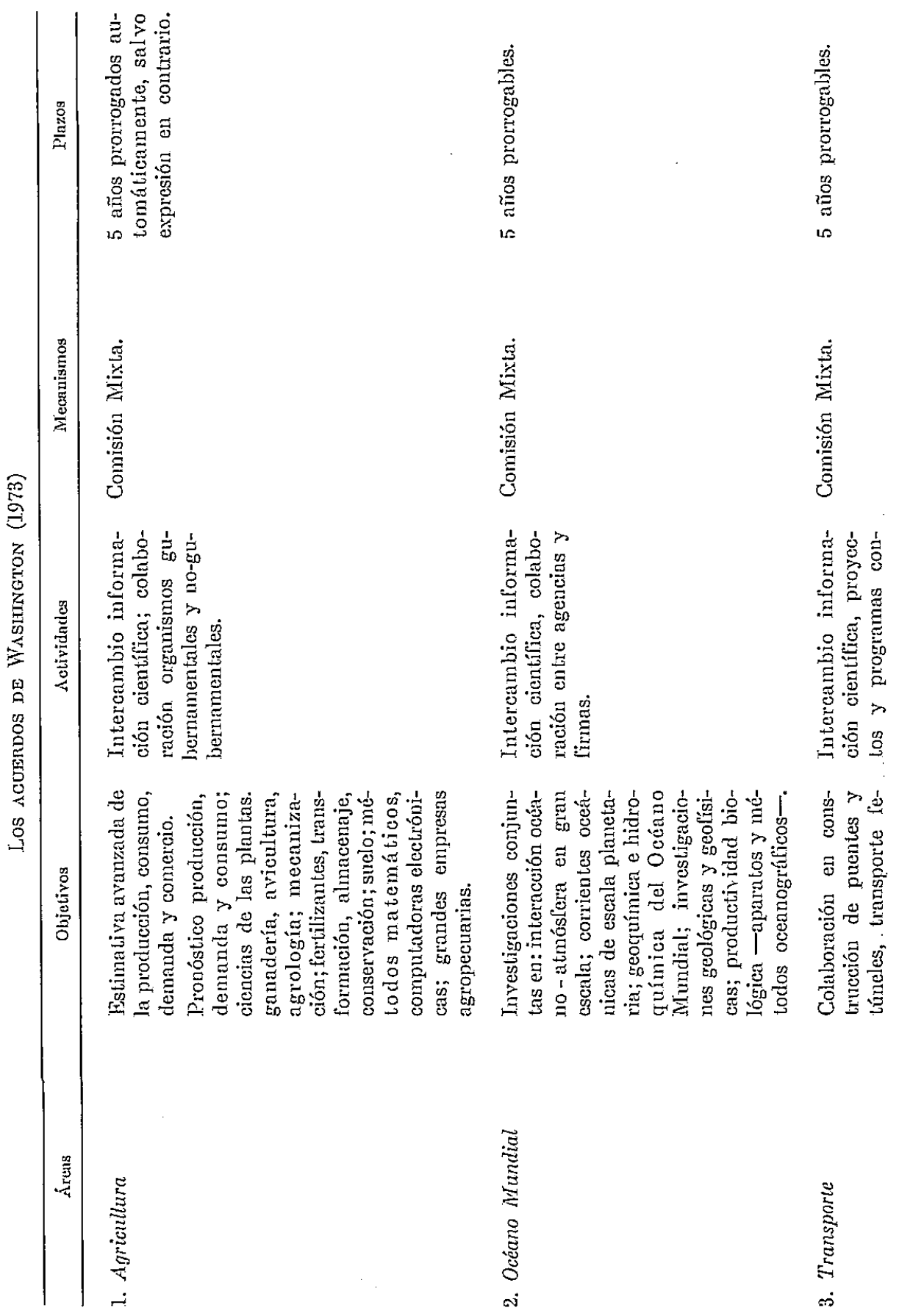


Horacio $H$. Godoy / Los acuerdos entre los E.E. U.U. y la U.R.S.S.

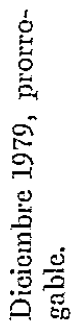

ֻே

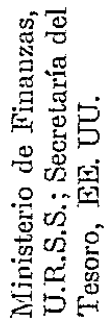

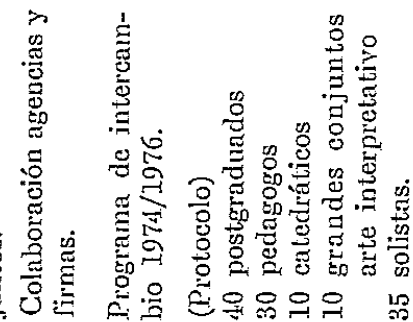

芯芯

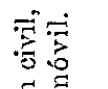

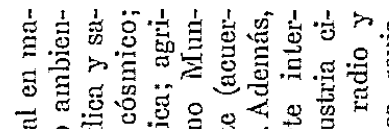

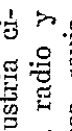

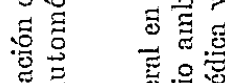

.

范

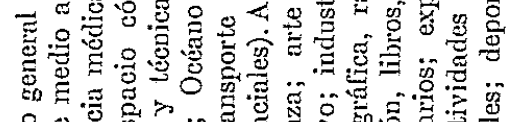

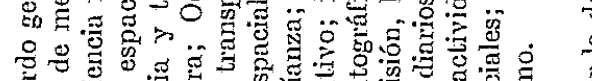

总

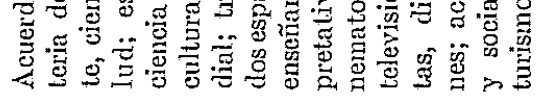

离

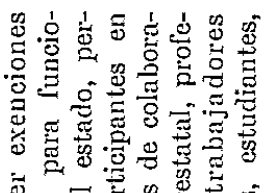

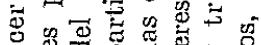

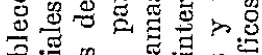

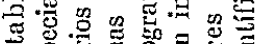

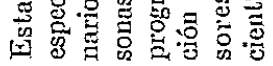

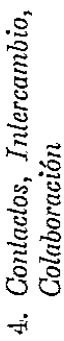

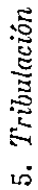


ESTUDIOS INTERNACIONALES

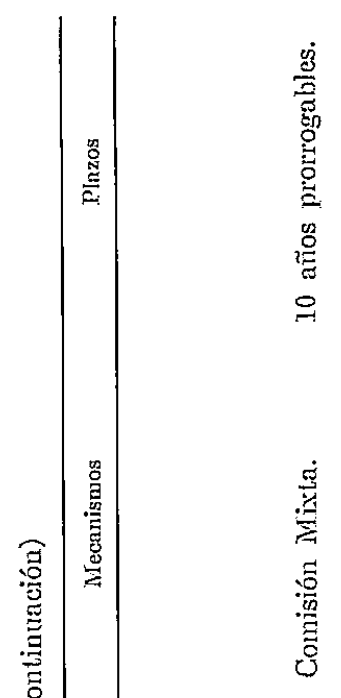

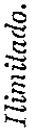

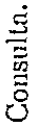

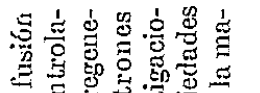

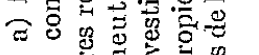

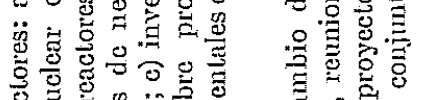

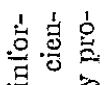

氖总㤩

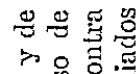

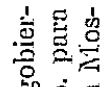

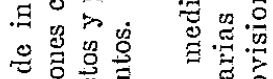

응응

DF

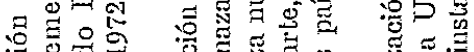

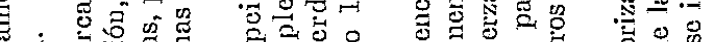

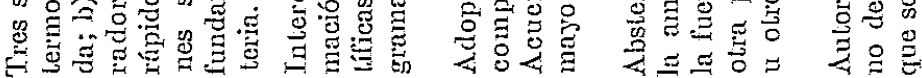

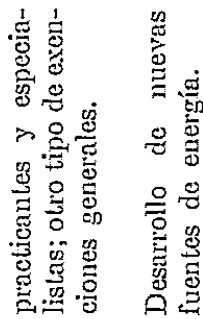

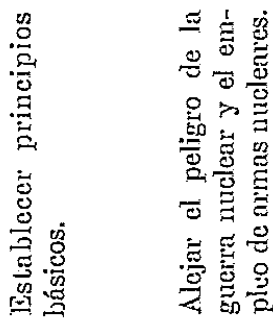

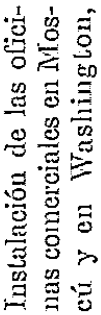

:

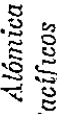

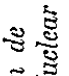

$\stackrel{2}{\approx}$

这这
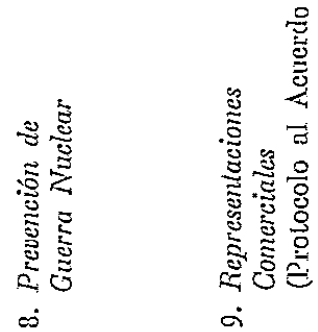
Horacio H. Godioy / Los acuerdos entre los E.E. U.U. y la U.R.S.S.

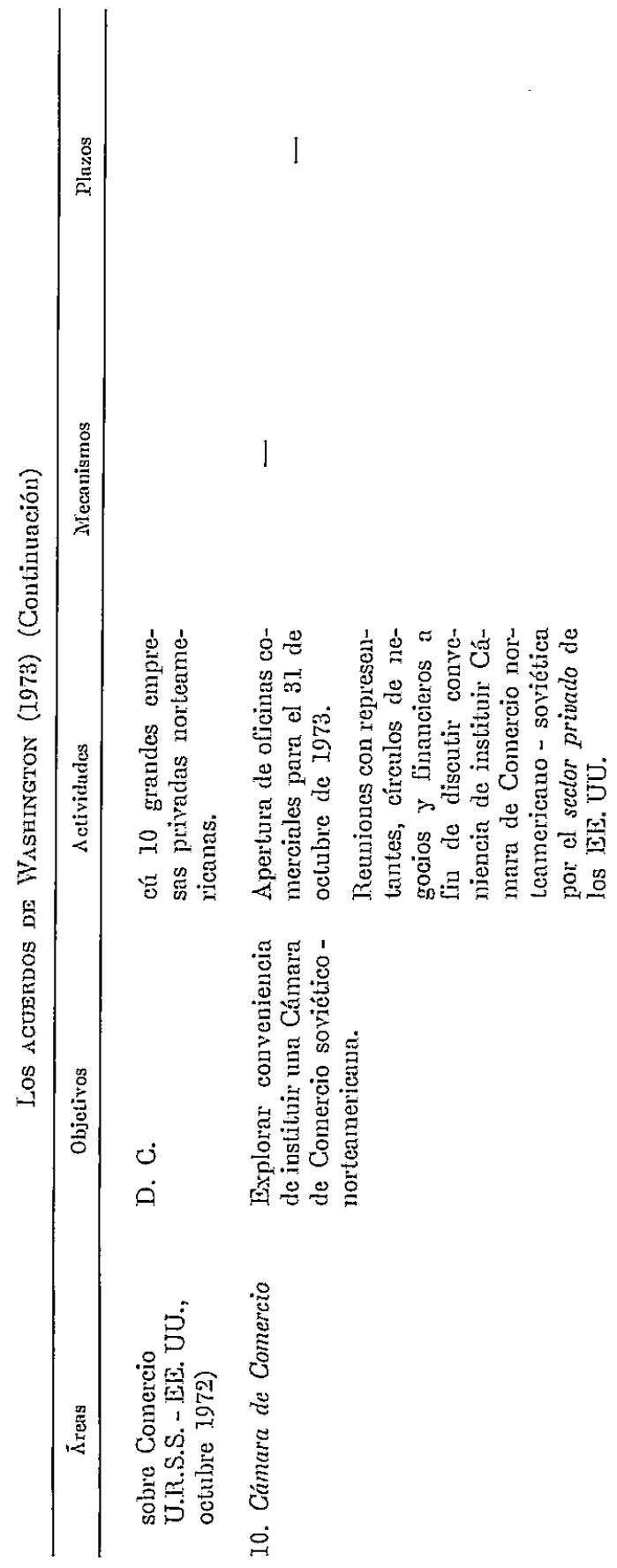


En esta ocasión, el representante soviético destacó los perjuicios causados por la "guerra fría" y puso de relieve la disposición del gobiemo de la Unión Soviética de poner fin a ese pasado "tanto en la política como en la economía".40

Señaló también Leonidas I. Brézhnev que ambos representantes de las superpotencias estaban de acuerdo en "dar nuevo impulso y apoyar al máximo a los medios empresariales de los Estados Unidos, y a los respectivos departamentos y organizaciones de la Unión Soviética en sus esfuerzos por abrir un nuevo y venturoso camino para la colaboración y el comercio mutuamente beneficiosos". ${ }^{41}$

Puede decirse que si los Acuerdos de Moscú tuvieron énfasis en los problemas de la paz y de la limitación de los armamentos estratégicos defensivos (ABMs), los Acuerdos de Washington pusieron énfasis en los aspectos comerciales. En octubre de 1972, los Estados Unidos y la Unión Soviética firmaron el Acuerdo sobre Comercio en base al cual el gobierno de la Unión Soviética autorizó la apertura en Moscú de representaciones de las siguientes empresas norteamericanas: ${ }^{42}$

Pullman Inc.

758.000 .000

Occidental Pctroleum .................

2.487.247.000

The Chasse Manhattan Bank ..........

30.703.610.000 (Activo)

General Electric Co. ............... 10.239.500.000

International Flarvester Co. ..........

3.493 .274 .000

Caterpillar Tractor Co. ..............

2.602 .178 .000

Hewlett - Packard Co. ..............

Engelhard Minerals and Chemichals Corp.

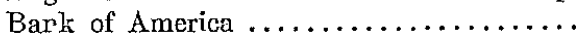

479.000 .000

First National City Bank

4.0.888.450.000 (Activo)

34.386.128.000 (Activo)

40Leonidas I. Brézhnev: loc. cit., p. 19.

4.1Leonidas I. Brézhnev: loc. cit., p. 20.

42Los datos del cuadro que se presenta a continuación, se han tomado de las fuentes siguientes: 1) los nombres de las diez empresas instaladas en Moscú: Protocolo Acerca de la Apertura de Representación Comercial de la URSS en Washington, y de una Oficina Comercial de los EE.UU. en Moscú, 22 de Junio, 1973. Conversaciones URSS-EE.UU., op. cit., pp. 70/71. 2) Las ventas anuales brutas de las empresas transnacionales que se instalan en Moscú: The Fortune Directory of the 500 Largest Industrial Corporations, Fortune: May, 1973, pp. 220/249. 3) El activo de los tres bancos más grandes del mundo: The Fortune Directory of the Fifty Largest Commercial Banking Companies, Fortune: July, 1973, pp. 120/123. Ver además: Horacio H. Godoy: La Administración Pública, las Empresas Transnacionales y el Grupo Andino, ESAP, Bogotá, 1973, pp. $19 / 38$. 
Horacio H. Godoy / Los acuerdos entre los E.E. U.U. y la U.R.S.S.

A la fecha de la firma de los Acuerdos de Washington, las autoridades soviéticas examinaban las peticiones de otras empresas norteamericanas para instalarse en la Unión Soviética.

\section{EL SIGNIFICADO DE LOS AGUERDOS}

\section{La interpretación de las partes}

Los Acuerdos de Moscú y de Washington pueden evaluarse en función de varios criterios:

a) Por la materia de los mismos, es decir, por su contenido (armas estratégicas, ciencia y técnica);

b) Por su volumen, o sea por la magnitud de las actividades que regulan. Por ejemplo, el monto probable del intercambio comercial;

c) Por el plazo establecido y la forma de regular su prórroga o suspensión (5 ó 10 años o indefinido);

d) Por su significado económico dentro de cada país signatario (cereales para la Unión Soviética y gas natural para los Estados Unidos);

e) Por sus efectos en las relaciones recíprocas entre las partes (limitación de armamentos estratégicos);

f) Por sus efectos en las relaciones con terceros países (prevención de guerra nuclear).

Las partes contratantes no han ahorrado palabras para interpretar elogiosamente el significado de los Acuerdos. En el Comunicado Conjunto de los Estados Unidos y de la Unión de Repúblicas Socialistas Soviéticas que se dio a publicidad al finalizar la visita del presidente Nixon a la Unión Soviética, el 29 de mayo de 1972, se distinguen dos aspectos de las negociaciones en Moscú.

En la primera parte, el Comunicado Conjunto se refiere a las relaciones bilaterales entre los Estados Unidos y la Unión de Repúblicas Socialistas Soviéticas; en la segunda parte, trata de la situación internacional.

En cuanto a las relaciones bilaterales -que son las que interesa destacar en esta parte del trabajo- las superpotencias asignan la máxima importancia a los Principios Básicos de las Relaciones Mutuas entre los Estados Unidos y la Unión de Repúblicas Socialistas Soviéticas. Estos principios y el conjunto de los Acuerdos de Moscú, 
constituyen lo que el presidente Nixon llamó "Tos cimientos de una nueva relación entre las dos naciones más poderosas de la tierra" ${ }^{43}$

Estos Principios Básicos "crean las premisas jurídico-internacionales para que las relaciones y la colaboración entre ambos países en todos Ios dominios de mutuo interés se asienten sobre una base sólida y duradera sin detrimento alguno para terceros países. La aplicación consecuente de estos principios en la práctica política de ambos estados coadyuvará a la sucesiva normalización de las relaciones soviético-norteamericanas y al saneamiento de la situación internacional". ${ }^{44}$

Sobre la base de los Principios anunciados, la Unión de Repúblicas Socialistas Soviéticas estima que en la reunión de Moscú se concluyó un número importante de convenios que "responden a los intereses de ambos estados, a las necesidades vitales de la humanidad y sirven por entero a fines pacíficos".45

Pero son, sobre todo, dos los aspectos que más se destacan por los voceros de las superpotencias: el tratado sobre limitación de los armamentos estratégicos y las negociaciones sobre el comercio soviético-norteamericano.

Con relación a la limitación de los armamentos estratégicos, el presidente Nixon informó al Congreso de los Estados Unidos, que en Moscú se había logrado "el principio del fin" de la era de la carrera armamentista creadora del peligro de una guerra nuclear. Dijo el presidente Nixon: "Dimos el primer paso hacia una nueva era de restricción mutuamente convenida y de limitación de armas entre las dos principales potencias nucleares". ${ }^{46}$

Más adelante agregó algo que tiene una importancia fundamental en la apreciación que pueda hacerse acerca de los Acuerdos de Moscú para las partes contratantes: "Desde el punto de vista de los Estados Unidos, al considerar lo que el equilibrio estratégico hubiese sido a fines de esta década de no haberse acordado la limitación de armas, resulta claro que los convenios impiden un importante desarrollo de la carrera armamentista, desarrollo que podría haber actuado en perjuicio nuestro, ya que no tenemos actualmente ningún programa de construcción para la categoría de armas congeladas y puesto que ningún nuevo programa de construcción hubiese podido producir nuevas armas de esa categoría durante el período de con-

43Informe al Congreso, en: "El Presidente Nixon en Moscú", op. cit., p. 29. 44EI CC del PCUS, el Presidium del Soviet Supremo de la URSS y el Consejo de Ministros de la URSS: Sobre los Resultados de las Negociaciones Soviético-Norteamericanas, en: "URSS: El Programa de Paz en Acción", op. cit., pp. $39 / 40$.

$45 I d$. ant.

46Informe al Congreso, en: "El Presidente Nixon en Moscú", loc. cit., p. 31. 
gelamiento" 47 . A pesar de la traducción deficiente del párrafo transcrito, queda claro que la limitación de armamentos estratégicos llegó para los Estados Unidos en un momento muy oportuno. ${ }^{48}$

Por su parte, las autoridades soviéticas expresaron respecto de este tema lo siguiente: "La firma del Tratado entre la Unión de Repúblicas Socialistas Soviéticas y los Estados Unidos sobre limitación de los sistemas de defensa anticoheteril y del Convenio Provisional sobre algunas medidas en el terreno de la limitación de los armamentos estratégicos ofensivos es un importantísimo medio que contribuye a atenuar el peligro de guerra nuclear, a frenar la carrera armamentista y abre perspectivas para llegar al desarme completo. Responde a los intereses de los pueblos soviético y norteamericano y de toda la humanidad". ${ }^{40}$

En cuanto a las negociaciones comerciales, las autoridades soviéticas han expresado que "la Unión Soviética se pronuncia por el desarrollo favorable de amplias relaciones comerciales y económicas con Estados Unidos, entendiendo que en este terreno se pueden encontrar soluciones mutuamente ventajosas".50

El presidente Nixon, por su parte, afirmaba en su comunicación al Congreso que "un mayor intercambio comercial norteamericanosoviético redundará igualmente en ventajas para nuestras dos naciones. Cuando los dos más importantes sistemas económicos del mundo empiecen a comerciar entre sí en escala mucho más considerable, los niveles de vida se elevarán en ambos países y los beneficios que ambos obtengan en la paz, serán mayores". ${ }^{51}$

Estas son, a grandes rasgos, las opiniones de las autoridades máximas de las superpotencias contratantes al finalizar las reuniones que condujeron a la firma de los Acuerdos de Moscú, en 1972.

Un año más tarde, se reunirían los protagonistas de esta histórica jornada en Washington, D.C. Al evaluar el año transcurrido, reafirmaron su fe en la reestructuración de las relaciones norteamericanosoviéticas. Ell secretario general del Comité Central del Partido Comunista de la Unión de Repúblicas Socialistas Soviéticas dijo en sus declaraciones a los miembros de la Comisión de Relaciones Exteriores del Senado de los Estados Unidos que "el año transcurrido ha confirmado la justeza de la línea de arreglo de las relaciones soviético-norteamericanas, trazada en los documentos suscritos como resultado de la entrevista con el presidente de los Estados Unidos, Richard Nixon, en Moscú".52

47 Id. ant..

48Td. ant.

49 Id. ant., p. 40.

ธoId. ant.

51Id. ant., p. 30.

ธ2Leonidas I. Brézhnev: Nuestro rumbo: La Paz y el Socialismo, op. cit., p. 9. 
En el Comunicado Conjunto Soviético-Norteamericano, dado a publicidad al finalizar las reuniones de Washington, en junio de 1973, los representantes de la Unión de Repúblicas Socialistas Soviéticas y de los Estados Unidos "subrayaron con satisfacción que los resultados del encuentro soviético-norteamericano, celebrado en mayo de 1972 en Moscú, merecieron la aprobación de otros estados y de la opinión pública mundial, como un gran aporte al fortalecimiento de la paz y la seguridad internacional, como freno a la carrera armamentista y un mejoramiento en la colaboración práctica de Estados Unidos con distinto sistema social". ${ }^{53}$

Con respecto a los Acuerdos de Washington, se mantienen las mismas líneas de interpretación, con la diferencia que los países del mundo subdesarrollado reciben con alguna sorpresa las declaraciones del secretario general del Comité Central del Partido Comunista de la Unión de Repúblicas Socialistas Soviéticas sobre la colaboración de las grandes empresas norteamericanas mencionadas anteriormente, ya que se han instalado en la Unión Soviética. ${ }^{54}$

A este respecto, dijo Leonidas I. Brézhnev que "ambas partes deben obtener beneficios sensibles y reales del desarrollo y la profundización de la colaboración económica y en general de las transacciones a largo plazo y de gran envergadura, cuyas negociaciones entre las organizaciones soviéticas y las grandes firmas norteamericanas hoy en día se adelantan o coronaron con éxito". ${ }^{55}$

En otra de sus intervenciones dijo Leonidas I. Brézhnev: "Por supuesto que el presidente Nixon y yo no hemos hablado acerca de qué compañía en concreto, podría colaborar mejor con la Unión Soviética. Pero hemos coincidido totalmente en que ambas partes deben dar nuevo impulso y aportar al máximo a los medios empresariales de los Estados Unidos y a los respectivos departamentos y organizaciones de la Unión Soviética en sus esfuerzos por abrir un nuevo y anchuroso camino para la colaboración y el comercio mutuamente beneficiosos".56

En síntesis, las altas partes contratantes, aunque estiman que todavía queda un largo camino por recorrer, reafirman su decisión de "emprender nuevos pasos importantes a fin de que sus relaciones sean, en la medida de lo posible, to más estables, y que la amis-

53Conversaciones URSS-EE.UU., Documentos, op. cit., pp. 5/6.

54 Ver página 41. Como un dato pintoresco, cabe señalar que las oficinas del Chasse Manhattan Bank en Moscú están ubicadas en la plaza Karl Marx No 1, como queriendo indicar simbólicamente que se instaló en el corazón mismo de Moscú.

${ }^{55 L e o n i d a s ~ I . ~ B r e ́ z h n e v: ~ I n t e r v e n c i o ́ n ~ d e ~ L e o n i d a s ~ I . ~ B r e ́ z h n e v ~ p o r ~ l a ~ T V ~}$ Norteamericana, el 24 de junio de 1973, en: "Nuestro Rumbo, La Paz y el Socialismo", op. cit., p. 26.

56 Leonidas I. Brézhnev: Entrevista con los Representantes del Mundo de los Negocios de los Estados Unidos el 22 de junio de 1973, id. ant., pp. 16/18. 
Horacio H. Godoy / Los acuerdos entre los E.E. U.U. y Ja U.R.S.S.

tad y la colaboración entre sus pueblos sea un factor permanente de paz internacional". ${ }^{57}$

El presidente Nixon fue invitado a visitar a la Unión Soviética durante el año 1974 y se espera que los contactos "en la cumbre" tengan un carácter sistemático. 58

\section{La interpretación de los Países No Alineados}

La Cuarta Conferencia de representantes de los Países No Alineados, celebrada en Argel del 5 al 9 de septiembre, aprobó una extensa Declaración Política ${ }^{59}$ compuesta de 97 puntos, de los cuales los puntos $9,10,11,12,13,14,15$ y $16,19,20,21$ y 61 se refieren en forma directa $o$ indirecta a los Acuerdos entre las superpotencias.

En primer lugar, reconocen que "el aumento de la distensión EsteOeste y los progresos realizados con respecto al arreglo en Europa de los problemas heredados de la Segunda Guerra Mundial, constituyen un éxito apreciable de las fuerzas de paz en el mundo -10-. Esta evolución se ha traducido en la intensificación de los contactos entre los Estados Unidos de América y la Unión de Repúblicas Socialistas Soviéticas -11 -

Consideran los Países No Alineados que "el acercamiento EsteOeste, las negociaciones de toda naturaleza actualmente en curso, los acuerdos recientemente concluidos o próximos a concluir, tienen por objeto esencial el de instaurar la cooperación en el cuadro de un sistema de seguridad colectiva fundada sobre los principios, los cuales, por encima de las diferencias ideológicas, tienden a presidir las relaciones internacionales" -12-. Los Países No Alineados "se felicitan de todos esos esfuerzos e iniciativas, considerándolos como una etapa positiva en el establecimiento de la paz" -13-.

Sin embargo, se reconoce en la mencionada Declaración Política que "si la distensión Este-Oeste ha tenido progresos, la confrontación de los pueblos con el colonialismo, la discriminación y el apartheid, la dominación y la ocupación extranjera, el neocolonialismo, el imperialismo y el sionismo, siguen siendo una realidad en nuestra época" -1.4-. Sostienen que la paz es un concepto indivisible, y que mientras subsistan los males señalados y las situaciones de guerras latentes o manifiestas, la paz se limitará a "Tas zonas prósperas del planeta" -16 -

57 Conversaciones URSS-EE.UU., Documentos, op. cit., p. 7.

58Leonidas I. Brézhnev: Intervención de Leonidas I. Brézhnev por la TV Norteamericana, el 24 de junio de 1973, op. cit., p. 33.

59 Declaración Política, IV Conferencia de Jefes de Estado o de Gobierno de los Países No Alineados, Argel, 5 al 9 de septiembre de 1973, en: "Política Internacional", Belgrado, No 563, 20-XI-1973, pp. 20/24. 
La paz no puede reducirse a un simple traslado geográfico de la guerra o del conflicto. Y la guerra no se limita solamente al conflicto abierto en términos militares. "La distensión sería precaria si no tuviera en cuenta los intereses de otros países" - 16-. Por ello, la Declaración Política expresa que no puede relegarse a más de la mitad de los países del mundo, que representan las dos terceras partes de la población mundial a vivir en una periferia del planeta, "condenada a la inseguridad y a la ley del más fuerte" -16-.

El concepto de seguridad internacional incluye como una de sus características esenciales la dimensión económica que "garantice a todos los países el derecho de llevar a la práctica sus programas de desarrollo al margen de agresiones y de todas otras formas de presión" -19-. Los Países No Alineados se empeñan en hacer "prevalecer los principios de seguridad económica en las relaciones internacionales" $-20-$.

El concepto de seguridad internacional es, además, un concepto universal que debería englobar a todas las regiones del mundo, y sería igual para todos los pueblos y todos los países -61-.

Esta concepción global y multisectorial de la seguridad internacional que tienen los Países No Alineados, supera en extensión y en contenido a la concepción de seguridad internacional de las superpotencias.

Por ello es que, en el fondo del pensamiento político mundial de los "terceros países" con respecto a los Acuerdos de Moscú y de Washington, consideran que el entendimiento entre los Estados Unidos y la Unión de Repúblicas Socialistas Soviéticas -y la consiguiente reestructuración de sus relaciones- constituyen una condición necesaria pero obviamente no suficiente para la paz y la seguridad mundial, tanto en sus aspectos militares cuanto en sus aspectos políticos y económicos.

Uno de los conceptos esenciales de la política internacional que sostienen los Países No Alineados es el que se refiere a su derecho soberano de ser reconocidos y admitidos en la toma de decisiones de alcance mundial. Estos países quieren "asegurar plenamente sus responsabilidades internacionales, y contribuir a la solución de los problemas de nuestra época que comprometen el destino de todos los pueblos del mundo" -26-y para ello reclaman el derecho a la participación en base a la igualdad en el proceso de toma de las decisiones que pudieran afectar a los países del mundo cualquiera sea su tamaño $-26-{ }^{60}$

coHoracio H. Godoy: Aspectos Teóricos del Proceso de Participación Política, en: "Colombia: hacia una Sociedad Participante", Editado por Diego Uribe Vargas, Horacio $\mathrm{H}$. Godoy y otros. Fundación para la Nueva Democracia, Bogotá, noviembre, 1973, pp. 13/35. 
Esta concepción mundial de la participación que proclaman los Países No Alineados, se relaciona con el apoyo total que estos países otorgan a la Organización de las Naciones Unidas. Después de senalar la universalización de la ONU con el reconocimiento de la República Popular China, y el de la República Federal Alemana y el de la República Democrática Alemana, estiman que la Organización Mundial puede constituir el instrumento eficaz para promover la paz y la seguridad internacionales, desarrollar la cooperación y salvaguardar los derechos y las libertades fundamentales" -74-.

La Declaración Política de Argel mantiene y desarrolla la concepción política mundial de los Países No Alineados, definida ya en otras conferencias anteriores, principalmente en la de Georgetown, Guyana, en agosto de 1972. En esta conferencia, celebrada dos meses después de la reunión de Moscú, los Países No Alineados se congratulaban con los procesos de apaciguamiento y normalización de relaciones entre las mayores potencias, pero señalaron que "éstos procesos deberían extenderse a todas las regiones del mundo sin excepción". Este "apaciguamiento -señalaron en aquella oportunidad- debe ir acompañado por la obligación de proceder a una creciente cooperación internacional y, en la medida de lo posible, ello debía conseguirse recurriendo cada vez más a las instituciones del sistema de las Naciones Unidas". Y concluía afirmando en forma categórica "tan sólo esto haría posible abordar la pronta solución de los problemas fundamentales del desarrollo económico, del desarme y de la paz internacional, que constituyen la mayor preocupación de todas las naciones". ${ }^{61}$

Indira Gandhi dijo en el discurso a la Cuarta Conferencia de los Países No Alineados que "Acaba de iniciarse una nueva era de apaciguamiento, y nosotros celebramos cierto progreso en ese sentido. Sin embargo, existen asimismo zonas de inestabilidad, fuentes de conflictos, exploraciones, injusticias y dominaciones".

Adam Malik, ministro de Relaciones Exteriores de Indonesia, dijo en esa ocasión que "la distensión y la coexistencia pacífica deben extenderse a todos los confines del mundo, a las relaciones entre todas las naciones".

Para finalizar esta parte, cuyo interés es innegable, permítaseme transcribir algunos de los párrafos del discurso pronunciado por el presidente Tito, ante la Cuarta Conferencia de Argel: "La atención del mundo entero se ve atraída hoy por las relaciones entre las grandes potencias, las cuales, debido a su gran poder, tienen una gran responsabilidad por la paz y la seguridad. Es natural que cele-

61Documentos de las Conferencias y reuniones de Ios Países No Alineados, 1961-1973, Secretaría de Informaciones del Consejo Ejecutivo Federal, Belgrado, 1973. 
bremos el progreso en su cooperación bilateral -económica, científica y de otra índole- que debe contribuir a la consolidación de la paz. Sin embargo, no debemos cerrar los ojos ante los serios problemas que todavía pesan sobre el mundo y cuya solución no se puede ceder sólo a un círculo estrecho de países. Y eso, aún menos, por el hecho de que las verdaderas soluciones son posibles únicamente si en su toma participan todos los países, y en todo caso, los que están directamente afectados. Si no se aplicara este método democrático, nos veremos constantemente enfrentados con los peligros que provienen de la práctica de resolver problemas sin la participación directa de los interesados. Tales soluciones suelen aportar sólo alivios pasajeros, pero al mismo tiempo llevan gérmenes de nuevas dificultades y conflictos". ${ }^{62}$

\section{LA NUEVA ERA DE LAS RELACIONES INTERNAGIONALES \\ Y LA COOPERACIÓN MUNDIAL PARA EL DESARROLLO}

La hipótesis central de este trabajo sostiene que los Acuerdos de Moscú y de Washington, firmados entre las dos superpotencias mundiales, constituyen la terminación del período de la "guerra fría" y la iniciación formal de una nueva era en el campo de las relaciones internacionales y de la política mundial. Esta hipótesis central se complementa con dos hipótesis auxiliares: una, afirma que el efecto de los Acuerdos de Moscú y de Washington no puede valorarse en sus últimas consecuencias sin tener en cuenta el contexto histórico de la era científico-tecnológica que ha alterado radicalmente el significado del espacio y el tiempo -tempo o timinghistóricos; dos: que los Acuerdos de Moscú y de Washington son condición necesaria, pero no suficiente, para el desarrollo de una nueva era en la política mundial en la que la paz, la seguridad, la justicia social y el desarrollo se aseguren mediante la efectiva participación de todos los países del mundo.

Como una hipótesis complementaria de la hipótesis auxiliar dos, podría agregarse la siguiente: tres: para una real universalización del principio de la seguridad internacional -en términos militares y económicos- es necesario que los principios generales que inspiran las relaciones entre las superpotencias, se extiendan, orienten y se apliquen a las relaciones entre los países industrializados y los países subdesarrollados a través de mecanismos efectivos de participación.

62Presidente Tito: El Gran Papel de los No Alineados en la Edificación de un Mundo Mejor y más Justo, Política Internacional, No 563, loc. cit., pp. 8/9. 
Horacio H. Godoy / Los acuerdos entre los E.E. U.U. y la U.R.S.S.

La distensión de las relaciones internacionales, basada en los Acuerdos de las superpotencias y sostenida además por otros acuerdos como los que se refieren a Vietnam, Berlín, etc., tienen un efecto directo en las políticas militares de las superpotencias y de los países aliados $y$, en consecuencia, se reflejarán también en los presupuestos militares del mundo. Para dar una idea de la fuerza financiera liberada por la distensión de las relaciones internacionales, señalaré algunas informaciones sobre el tema:

Gastos militares en el mundo

(Millones de dólares, valor corriente)

\begin{tabular}{ccccc}
\hline 1961 & 1962 & 1963 & 1964 & 1965 \\
119.000 & 132.000 & 138.000 & 139.000 & 142.000 \\
\hline 1966 & 1967 & 1968 & 1969 & 1970 \\
159.000 & 178.000 & 191.000 & 200.000 & 208.000 \\
\hline
\end{tabular}

El total de gastos militares para la década comprendida entre los años 1961/1.970 ascendió a dólares 1.606.000.000.000, es decir, un billón seiscientos seis mil millones de dólares. En el año 1971 se gastaron 21.6 mil millones de dólares, lo que eleva el monto total de los gastos militares desde 1961 a 1971, a dólares 1.822.000.000.000, o sea un billón ochocientos veintidós mil millones de dólares. En la terminología inglesa equivalen a u\$s 1,8 trillones. $^{63}$

La distribución de estos gastos según países industrializados y países subdesarrollados por una parte, y por la otra entre países miembros de la Organización del Tratado del Atlántico Norte (NATO) y de los países miembros del Pacto de Varsovia, es la siguiente:

Gastos mirtiates EN EL arundo

(Miles de millones de dólares, valor corriente)

\begin{tabular}{|c|c|c|}
\hline Total mundial & US\$ & 1.606 .000 .000 .000 \\
\hline Industrializados & US\$ & 1.430 .000 .000 .000 \\
\hline Subdesarrollados & US\$ & 176.000 .000 .000 \\
\hline NATO $\ldots \ldots \ldots \ldots \ldots \ldots \ldots \ldots \ldots$ & US\$ & 878.000 .000 .000 \\
\hline PActo de Varsovia $\ldots \ldots \ldots \ldots \ldots \ldots \ldots$ & USS & 544.000 .000 .000 \\
\hline
\end{tabular}

Estas cifras representan gastos militares totales de 120 países. El aumento constante de los presupuestos de gastos militares se debió a tres causas principales: precios más altos de los equipos militares; la incorporación de casi 4 millones de hombres a las fuerzas arma-

63United States Arms Control and Disarmament Agency: World Military Expenditures, 1971, pp. 1, 2, 9. 
das durante el período 1961/1970 y las grandes inversiones en tecnología moderna para la elaboración de armamentos más perfeccionados. Todas estas causas, estimuladas por las tensiones internacionales de la guerra fría.

Los gastos militares de los Estados Unidos, ocasionados en más de un $25 \%$ por la guerra de Vietnam, han sido estimados en u\$s 553.000 millones de dólares para los años 1.965/1972, es decir, durante ese período de ocho años un promedio de u\$s $69.000 \mathrm{mi}-$ llones de dólares por año, equivalente al producto interno bruto anual combinado de la Argentina, Brasil y Chile y a dos veces el producto interno bruto de los seis países del Grupo Andino, y la suma total para los ocho años, superior al producto interno bruto de la Unión Soviética para el año 1970. ${ }^{\text {4 }}$

La nueva era de las relaciones internacionales significa en consecuencia, no sólo la distensión de las relaciones internacionales debido a la superación de los esquemas mentales y estratégicos de la "guerra fría", ni tampoco solamente el incremento del intercambio comercial y científico-tecnológico entre los Estados Unidos y la Unión Soviética. La nueva era significará la liberación de recursos financieros y tecnológicos y de organización y dirección -la supercapacidad de las superpotencias- y la necesidad urgente de una reorientación inmediata y productiva de dichos recursos hacia los fines pacíficos del desarrollo.

La capacidad integral de las superpotencias es una capacidad de escala mundial. Si se trabaja con esa capacidad de escala mundial, pero con una perspectiva o concepción estrechamente nacionalista, estaremos una vez más en presencia de concepciones imperialistas: que no son otra cosa que la acción de un país en escala mundial, persiguiendo intereses nacionales. El desafío que enfrentan los países del mundo es cómo canalizar la energía liberada por la paz hacia fines de construcción del nuevo orden mundial del siglo xxr. ${ }^{65}$

Se dijo anteriormente que el mundo empequeñecido -transformado ya en una "aldea global" según la feliz expresión de McLuhan- y en un acelerado proceso de transformaciones históricas, no puede tolerar la guerra, pero tampoco puede descuidar la construcción de la paz.

Dijo Leonidas I. Brézhnev en uno de los discursos clurante su visita a Washington: "Dentro de dos años, los cosmonautas sovié-

64SIPRI Yearbook, 1972, op. cit., pp. 54/55.

65El Institute of World Order con sede en Nueva York, realiza estudios para la elaboración de Modelos de Orden Mundial para la década de 1990/1999. Ocho grupos de estudios se reúnen desde hace algunos años y ya han producido sus primeros modelos, que están listos para su publicación. Ver: Ian Baldwin: Thinking About a New World Order for the Decade of 1990, War Peace Report, January, I970. 
Horacio H. Godoy / Los acuerdos entre los E.E. U.U. y Ia U.R.S.S.

ticos y norteamericanos volarán al Cosmos para realizar el primer grande experimento conjunto en la historia de la humanidad. Ellos saben que desde allá, desde el Cosmos, nuestro planeta parece aứn más hermoso, aunque pequeño". Y agregó: "Nuestro planeta es lo bastante grande para que en él podamos vivir en paz, pero demasiado chico para exponerlo a los peligros de guerra nuclear".

En otra de sus intervenciones, dijo el líder soviético: "Todos nosotros venimos desechando en los últimos años las viejas nociones en punto a ese problema ( La colaboración económica entre diversos países). Lo que es natural, pues las viejas formas de relaciones económicas ya no responden a las demandas del tiempo. Nueva es la escala de la economía de algunos países. Se opera a toda marcha la revolución científico-técnica impulsada por las grandes realizaciones del genio y el trabajo humanos". Y añadió más adelante: "¿Pero hallan estas nuevas demandas pleno reflejo en la práctica de las relaciones económicas internacionales? Creo que no. Y no por falta de demandas y posibilidades económicas reales, ni tampoco porque a veces, nuestras nociones al respecto van rezagadas de las nuevas realidades de la vida económica. Lo principal radica en otra cosa: radica en las condiciones políticas, en las relaciones políticas, que durante largo tiempo han obstaculizado el ensanche de la colaboración recíprocamente provechosa entre nuestros países". ${ }^{60}$

Me ha parecido conveniente citar estas expresiones de Leonidas I. Brézhnev, porque constituyen un claro ejemplo de la necesidad de revisar y actualizar el pensamiento -teoría y conceptos- económico acerca de las nuevas realidades en este sector, sino también -y tal vez con mucha mayor urgencia-, actualizar y revisar el pensamiento político, en escala mundial.

La nueva era significa esencialmente nueva escala de los fenómenos internacionales. Una creciente interrelación de la vida de los países, en la que superpotencias, empresas transnacionales y una constante proliferación de estados jurídicamente independientes, constituyen los actores cada vez más poderosos y cada vez más impacientes, según su posición relativa en nuestro empequeñecido mundo.

El monopolio de la política mundial parece ser una de las antiutopías que se destruye a sí misma. El duo-polio de la política munclial parece reunir los caracteres propios de las "profecías de autodestrucción” ${ }^{37}$. El mundo parece estar - datrapado?, ¿protegido?p. 18

${ }^{6}$ Leonidas I. Brézhnev: Nuestro rumbo: La Paz y el Socialismo, op. cit.,

G7Forst Afheldt: Development of Some Preconditions for Non-Violent International Relations, Mimeografiado, pp. 16/25, sin fecha. 
por un sistema en el que "el juego de la suma múltiple" rige las relaciones internacionales ${ }^{68}$. En esta coyuntura histórica de la humanidad, parecería que no habrá vencedores ni vencidos, que todos seremos ganadores y todos participaremos en algún modo en el sacrificio de bienes muy apreciados, en forma y proporciones distintas, porque tanto el triunfo final como la derrota final, también se han universalizado, también alcanzaron la escala mundial característica de nuestra era científico-tecnológica.

El escenario mundial contemporáneo presenta grandes problemas; $y$ en este escenario mundial se mueven grandes actores. La nueva era de las relaciones internacionales, que ofrece los fundamentos de la política mundial del siglo xxr, espera grandes soluciones, cuya escala mundial sea adecuada a la escala mundial de los problemas y del potencial extraordinario de los grandes actores. Pero éstos no están solos. La conferencia de Argel es sólo una de las expresiones de inquietud y de cautela frente a la "luna de miel" de los gigantes.

Con razón se ha dicho que, nosotros -en América Latina-, nos preocupamos mucho cuando los Estados Unidos y la Unión Soviética se enfrentan con algunos conflictos serios; pero cuando los Estados Unidos y la Unión Soviética se ponen de acuerdo, nosotros en América Latina nos preocupamos mucho más.

¿Qué se quiere significar con esta expresión de base popular latinoamericana? Que las "reglas de juego" según la teoría de los conflictos, presentan las alternativas a los países pequeños, cuando los grandes discuten o pelean. Claro que esta alternativa desaparece - para los grandes y los pequeños- si el conflicto entre las superpotencias alcanza al nivel de las armas estratégicas. Pero similar razonamiento deberíamos hacer para los tiempos de paz. La paz contemporánea, la paz de la era científico-tecnológica también es una paz nuclear. Paz en escala, diríamos. $Y$ en este caso las grandes potencias deben realizar su esfuerzo supremo para comprender que en la aldea global vivimos todos y que en la era espacial, científicotecnológica o era nuclear no tiene justificativo alguno la existencia de "cien países y dos mil millones de seres" sumergidos en las penurias del subdesarrollo. ${ }^{69}$

68Karl W. Deustch: The Analysis of International Relations, Prentice Hall, New Jersey, 1968, pp. 114/124. El Secretario de Estado norteamericano ha expresado muy bien esta situación especial en que se encuentran las dos superpotencias: "we are at one and the same time adversaries and partners in the preservation of peace" (somos al mismo tiempo adversarios y socios en la preservación de la paz). Ver Time, November 5, 1973, p. 7.

${ }^{69}$ Robert S. McNamara: Cien países. Dos Mil Millones de Seres. La Dimensión del Desarrollo, Tecnos, Madrid, 1973. 